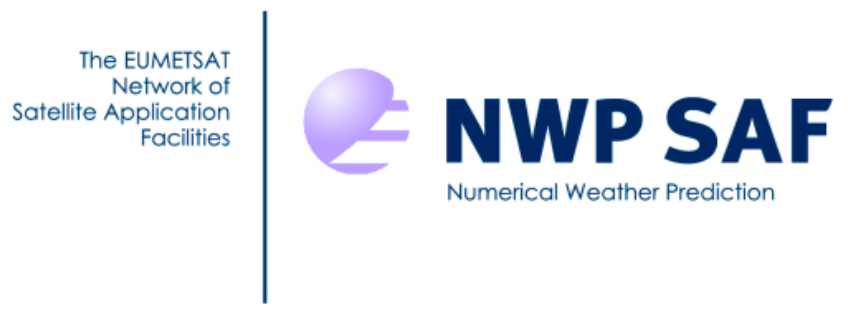

Document NWPSAF-KN-VS-014

Version 1.0

05-08-2015

\title{
On mesoscale analysis and ASCAT ambiguity removal
}

Wenming Lin ${ }^{1}$, Marcos Portabella ${ }^{1}$, Jur Vogelzang ${ }^{2}$, Ad Stoffelen $^{2}$, Anton Verhoef $^{2}$

1. Institut de Ciències del Mar (ICM-CSIC), Barcelona, Spain

2. KNMI, De Bilt, The Netherlands

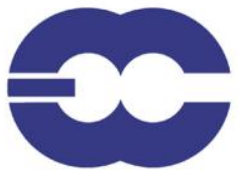




\begin{tabular}{|c|c|c|c|c|}
\hline 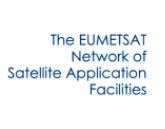 & (2) NWP SAF & $\begin{array}{l}\text { On mesoscale analysis and } \\
\text { ASCAT ambiguity removal }\end{array}$ & $\begin{array}{l}\text { Doc ID } \\
\text { Version } \\
\text { Date }\end{array}$ & $\begin{array}{l}: \text { NWPSAF-KN-VS-014 } \\
: 1.0 \\
: 05-08-2015\end{array}$ \\
\hline
\end{tabular}

\section{On mesoscale analysis and ASCAT ambiguity removal}

Wenming Lin ${ }^{1}$, Marcos Portabella ${ }^{1}$, Jur Vogelzang ${ }^{2}$, Ad Stoffelen $^{2}$, Anton Verhoef ${ }^{2}$

1. Institut de Ciències del Mar (ICM-CSIC), Barcelona, Spain.

2. KNMI, The Netherlands

This documentation was developed within the context of the EUMETSAT Satellite Application Facility on Numerical Weather Prediction (NWP SAF), under the Cooperation Agreement dated 29 June 2011, between EUMETSAT and the Met Office, UK, by one or more partners within the NWP SAF. The partners in the NWP SAF are the Met Office, ECMWF, KNMI and Météo France.

Copyright 2015, EUMETSAT, All Rights Reserved.

\begin{tabular}{|c|c|l|l|}
\hline \multicolumn{3}{|c|}{ Change record } \\
\hline Version & Date & $\begin{array}{l}\text { Author / } \\
\text { changed by }\end{array}$ & \\
\hline 0.1 & $22-04-2015$ & Wenming Lin & Initial draft \\
\hline 0.2 & $05-06-2015$ & $\begin{array}{l}\text { Marcos } \\
\text { Portabella }\end{array}$ & Review \\
\hline 0.3 & $03-07-2015$ & $\begin{array}{l}\text { Jur Vogelzang } \\
\text { Ad Stoffelen } \\
\text { Anton Verhoef }\end{array}$ & Review \\
\hline 1.0 & $05-08-2015$ & $\begin{array}{l}\text { Marcos } \\
\text { Portabella } \\
\text { Ad Stoffelen }\end{array}$ & Review \\
\hline & & & \\
\hline & & & \\
\hline & & & \\
\hline
\end{tabular}




\begin{tabular}{|c|c|c|c|c|}
\hline 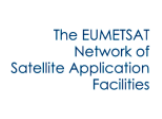 & Z NWP SAF & $\begin{array}{l}\text { On mesoscale analysis and } \\
\text { ASCAT ambiguity removal }\end{array}$ & $\begin{array}{l}\text { Doc ID } \\
\text { Version } \\
\text { Date }\end{array}$ & $\begin{array}{l}: \text { NWPSAF-KN-VS-014 } \\
: 1.0 \\
: 05-08-2015\end{array}$ \\
\hline
\end{tabular}

\section{Contents}

1 INTRODUCTION ......................................................................................................................................................................................4

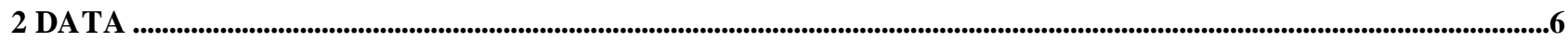

3 2DVAR AMB IGUITY REMOVAL SCHEME .......................................................................................................................................

4 ESTIMATION OF ECMWF BACKGROUND AND ASCAT OBS ERVATION ERRORS ........................................10

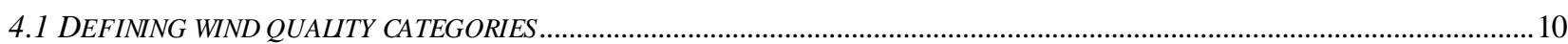

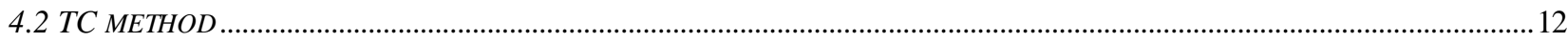

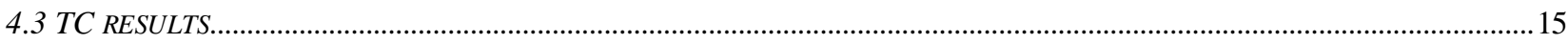

5 ECMWF BACKGROUND ERROR STRUCTURE FUNCTIONS ..................................................................................19

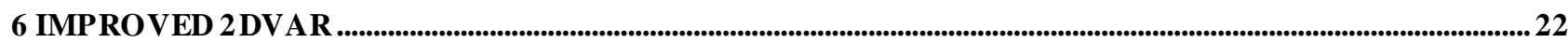

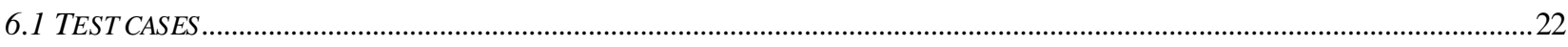

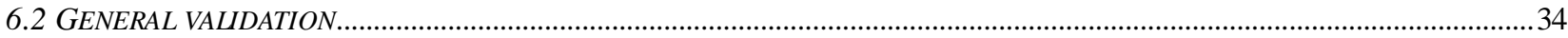

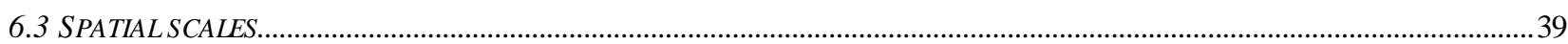

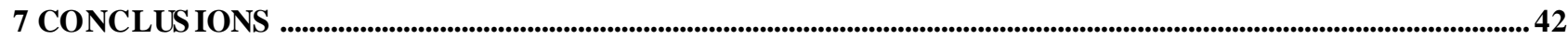

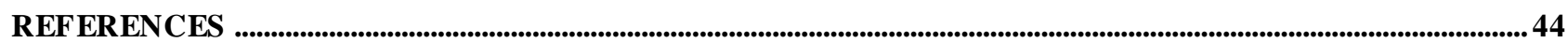




\begin{tabular}{|c|c|c|c|c|}
\hline 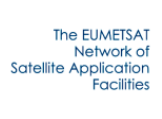 & Z NWP SAF & $\begin{array}{l}\text { On mesoscale analysis and } \\
\text { ASCAT ambiguity removal }\end{array}$ & $\begin{array}{l}\text { Doc ID } \\
\text { Version } \\
\text { Date }\end{array}$ & $\begin{array}{l}: \text { NWPSAF-KN-VS-014 } \\
: 1.0 \\
: 05-08-2015\end{array}$ \\
\hline
\end{tabular}

\section{Introduction}

In the so-called two-dimensional variational ambiguity removal (2DVAR) scheme [Vogelzang et al., 2010], the scatterometer observations and the model background (from the European Centre for Medium-range Weather Forecasts, ECMWF) are combined using a two-dimensional variational approach, similar to that used in meteorological data assimilation, to provide an analyzed wind field. Since scatterometers provide unique mesoscale information on the wind field, mesoscale analysis is a common challenge for 2DVAR and for mesoscale data assimilation in 4D-var or 3Dvar, such as applied using the Integrated Forecasting System (IFS) at ECMWF, Meteo France or in the HIRLAM project (www.hirlam.org). This study elaborates on the common problem of specifying the observation and background error covariances in data assimilation.

The second step of 2DVAR involves selecting at each wind vector cell (WVC), the scatterometer wind vector ambiguity which lies closest to the analysis, resulting in a final selected scatterometer wind field. The wind inversion for the Advanced Scatterometers onboard Metop-A and Metop-B (i.e, ASCAT-A and ASCAT-B, respectively) generally yields two solutions (ambiguities) with similar wind speed values and opposite wind directions. Occasionally, however, the wind inversion leads to 3 or 4 ambiguities. This happens when the backscatter signal is not dominated by the area mean wind modelled by the Geophysical Model Function or GMF), but mainly by increased local wind variability.

In general, 2DVAR proves to be effective in removing the ASCAT wind ambiguities. However, the wrong wind direction ambiguity can be selected when there are two or more local ambiguities and the background field supports the wrong solution, e.g., in case of mislocated storms, frontal (convergence) areas or missing mesoscale systems. The dual ASCAT ambiguities of $\sim 180$ degrees provide two almost equally likely solutions, which thus do not add much complementary information in the analysis step to correct for the erroneous background field. However, the specification of appropriate background error structure functions may lead to structural changes in the analysis field and thus reach spatial consistency with the overall scatterometer input [Stoffelen et al., 2000].

The influence of the ECMWF background field can be controlled by the 2DVAR parameters. It is decreased by increasing the background error variance, by decreasing the observation error variance, by increasing the background error correlation length or by decreasing the observation gross error probabilities [Vogelzang and Stoffelen, 2011a]. The current 2DVAR scheme in the 


\begin{tabular}{|c|c|c|c|c|}
\hline 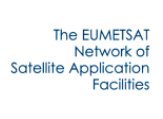 & $\angle$ NWP SAF & $\begin{array}{l}\text { On mesoscale analysis and } \\
\text { ASCAT ambiguity removal }\end{array}$ & $\begin{array}{l}\text { Doc ID } \\
\text { Version } \\
\text { Date }\end{array}$ & $\begin{array}{l}: \text { NWPSAF-KN-VS-014 } \\
: 1.0 \\
: 05-08-2015\end{array}$ \\
\hline
\end{tabular}

ASCAT wind data processor (AWDP) assumes homogeneous and isotropic error correlations described by Gaussian structure functions with adjustable range and rotation/divergence ratio. Fewer ambiguity removal errors over a frontal area have been achieved in [Vogelzang and Stoffelen, $2011 a$ ] by better specification of the static background error correlations. The current 2DVAR also uses constant background and observation standard deviation (SD) errors (i.e., $\varepsilon_{\mathrm{b}}=2.0 \mathrm{~m} / \mathrm{s}$ and $\varepsilon_{0}=$ $1.8 \mathrm{~m} / \mathrm{s}$, respectively).

ECMWF, however, specifies situation-dependent background errors, which are simulated by an ensemble of forecasts (EDA). Bonavita et al. (2012) suggest that adaptive background errors from EDA account for significant deterministic analysis improvement in 4D-var. According to [ $L$ in et al., 2015a], ECMWF winds are more erratic than ASCAT winds in rainy and high-wind-variability areas. Such areas may be identified by an increased wind inversion residual (MLE) or a negative spatial singularity exponent (SE). Following the quality indicators (MLE and SE) developed to improve the ASCAT wind quality control [Lin et al., 2015a], the background and observation errors are re-estimated as a function of these two quality-sensitive parameters by performing triple collocation (TC) analysis on a set of collocated buoy, ASCAT and ECMWF data. Application in 2DVAR results in a situation-dependent 2DVAR scheme. Near the sea surface, EDA background errors may be verified with ASCAT-derived background errors, providing a statistical and spatial validation of the simulated EDA errors.

Last, but not least, we note that the objective of 2DVAR is different from the objective of an ECMWF analysis. In 2DVAR we aim for analysis of the mesoscales observed by ASCAT, i.e., typically $25 \mathrm{~km}$, while in 4D-var analysis ECMWF aims to initialize the relevant degrees of freedom in the model domain. We will show that these objectives may result in different analyses.

In this study, an adaptive 2DVAR approach using empirical background error structure functions and situation-dependent observation/background errors is proposed to improve the current ASCAT ambiguity removal. Section 2 briefly describes the different types of wind and rain data sources used in this study. Section 3 summarizes the ASCAT 2DVAR methodology. In Section 4, a modified TC approach is presented and used to estimate the background and ASCAT errors as a function of two quality-sensitive parameters, MLE and SE. In section 5, the background error structure function is estimated from the autocorrelation of observed scatterometer wind components minus ECMWF forecasts. Section 6 evaluates the performance of the proposed AR approach using an extended collection of particularly challenging wind cases and collocated ASCAT-buoy winds. Finally, the conclusions can be found in section 7. 


\begin{tabular}{|c|c|c|c|c|}
\hline 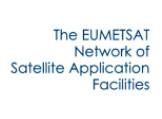 & Z NWP SAF & $\begin{array}{l}\text { On mesoscale analysis and } \\
\text { ASCAT ambiguity removal }\end{array}$ & $\begin{array}{l}\text { Doc ID } \\
\text { Version } \\
\text { Date }\end{array}$ & $\begin{array}{l}: \text { NWPSAF-KN-VS-014 } \\
: 1.0 \\
: 05-08-2015\end{array}$ \\
\hline
\end{tabular}

\section{Data}

The data set in this study consists of three years (March 2009 - February 2012) of ASCAT 12.5-km Level 2 (L2) data collocated with ECMWF forecasts and moored buoy winds. The ASCAT data in Binary Universal Format Representation (BUFR) are provided by the European Organisation for the Exploitation of Meteorological Satellites (EUMETSAT) Ocean and Sea Ice Satellite Application Facility (OSI SAF). The ECMWF forecast winds are acquired by interpolating in space and time three ECMWF 3-hourly forecast winds on a $0.5625^{\circ}$ lat/lon grid to the ASCAT data acquisition location and time. ASCAT L2 BUFR files already include ECMWF winds. The buoys used in this study include the National Data Buoy Center (NDBC) moored buoys off the coasts of U.S.A., the Ocean Data Acquisition System (ODAS) buoys in the north-east Atlantic and British Isles inshore waters, the National Oceanic Atmospheric Administration (NOAA) Tropical Ocean Atmosphere (TAO) buoy arrays in the tropical Pacific, the Japan Agency for Marine-Earth Science and Technology (JAMSTEC) Triangle Trans-Ocean Buoy Network (TRITON) buoys in the western Pacific, the Prediction and Research Moored Array in the Atlantic (PIRATA), and the Research Moored Array for African-Asian-Australian Monsoon Analysis and Prediction (RAMA) at the tropical Indian Ocean.

Two different buoy data sources are examined. The first data set consists of buoy winds that are reported hourly by averaging the wind measurements over 10 minutes, distributing them through the Global Telecommunication System (GTS) stream, and subsequently quality controlled and archived at the ECMWF Meteorological Archival and Retrieval System (MARS). Note that the individual buoy observations are segregated into $1 \mathrm{~m} / \mathrm{s}$ speed bins and $10^{\circ}$ direction bins. The collocation criteria for this buoy data set are 30 minutes distance in time and $25-\mathrm{km}$ distance in space from the ASCAT measurements. Only the ASCAT measurement closest to the buoy acquisition is used in case more than one WVC meets the collocation criteria. The total amount of collocations with MARS buoy winds is about 80,000. The second data set consists of continuous ten-minute (10- $\mathrm{min})$ buoy wind measurements. This data set is available online from the NOAA site http://www.pmel.noaa.gov/. The collocation criteria for continuous buoy winds are 5 minutes distance in time and $25 \mathrm{~km}$ distance in space from the ASCAT measurements. In addition, a series of 25 ten-minute (+/- 2 hours) continuous buoy measurements are recorded in each collocation to compute the $25-\mathrm{km}$ equivalent buoy winds [Lin et al., 2015a], further referred to as mean buoy winds. Due to the lack of ODAS and TRITON continuous buoy winds and the unavailability of 


\begin{tabular}{|c|c|c|c|c|}
\hline 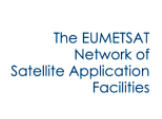 & Z NWP SAF & $\begin{array}{l}\text { On mesoscale analysis and } \\
\text { ASCAT ambiguity removal }\end{array}$ & $\begin{array}{l}\text { Doc ID } \\
\text { Version } \\
\text { Date }\end{array}$ & $\begin{array}{l}: \text { NWPSAF-KN-VS-014 } \\
: 1.0 \\
: 05-08-2015\end{array}$ \\
\hline
\end{tabular}

some wind measurement in the 25 ten-minute series, the total amount of collocations with continuous buoy winds is about 42,000 . In all buoy data sets, the measured wind vectors at a given anemometer height are converted to 10-m equivalent neutral winds using the Liu-Katsaros-Businger (LKB) model [Liu et al., 1979] in order to make them comparable to ASCAT and ECMWF winds.

Furthermore, part of the ASCAT BUFR files are collocated with Tropical Rainfall Measuring Mission's (TRMM) Microwave Imager (TMI) rain data, which are obtained from the Remote Sensing Systems Web site (www.remss.com/missions/tmi). The used TMI data (version 4) are provided as daily maps at a pixel resolution of $0.25^{\circ}$ (about $25 \mathrm{~km}$ ). The collocation criteria for TMI rain data are less than 30 -min time difference and $0.25^{\circ}$ spatial distance from the ASCAT measurement. 


\begin{tabular}{|c|c|c|c|c|}
\hline 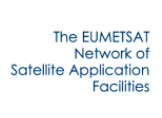 & Z NWP SAF & $\begin{array}{l}\text { On mesoscale analysis and } \\
\text { ASCAT ambiguity removal }\end{array}$ & $\begin{array}{l}\text { Doc ID } \\
\text { Version } \\
\text { Date }\end{array}$ & $\begin{array}{l}: \text { NWPSAF-KN-VS-014 } \\
: 1.0 \\
: 05-08-2015\end{array}$ \\
\hline
\end{tabular}

\section{2DVAR ambiguity removal scheme}

2DVAR consists of two steps: first, the scatterometer observations and the model background (i.e., ECMWF) are combined using a two-dimensional (2D) variational approach (similar to that used in data assimilation, but simplified to $2 \mathrm{D}$ and with only ambiguous scatterometer winds as observed input) to provide an analyzed wind field; then at each WVC location, the ASCAT wind ambiguity which lies closest to the analysis is selected resulting in a final ASCAT selected wind field.

2DVAR follows basic premises in meteorological variational data assimilation. Given a set of scatterometer wind solutions (ambiguities) $\mathbf{x}_{o}^{k}$ with ambiguity index $k$ and the background winds $\mathbf{x}_{b}$, the analyzed wind vector results from minimizing the following cost function [De Vries et al., 2005]

$$
J\left(\mathbf{x}_{o}^{k}, \mathbf{x}, \mathbf{x}_{b}\right)=J_{o}\left(\mathbf{x}_{o}^{k}, \mathbf{x}\right)+J_{b}(\mathbf{x})
$$

where $J_{\mathrm{o}}$ is the observational term and $J_{\mathrm{b}}$ is the background term. For the sake of computational efficiency, the analysis increment $\delta \mathbf{x}=\mathbf{x}-\mathbf{x}_{b}$ is optimized instead of the state vector $\mathbf{x}$ itself. Consequently, $J_{\mathrm{o}}$ is given by [Stoffelen and Anderson, 1997a]

$$
J_{o}=\sum_{i, j}^{N_{1}, N_{2}}\left\{\sum_{k}\left[\frac{M_{i j}\left[\Delta t_{i j}-\Delta t_{i j, k}^{(o)}\right)^{2}}{\sigma_{t}^{2}}+\frac{\left(\Delta l_{i j}-\Delta l_{i j, k}^{(o)}\right)^{2}}{\sigma_{l}^{2}}-2 \ln p_{k}\right]^{-\lambda}\right\}^{-1 / \lambda}
$$

with $(i, j)$ the indices of the 2DVAR grid cell, $N_{1}$ and $N_{2}$ the number of 2DVAR grid cells across and along the satellite track direction, and $M_{\mathrm{ij}}$ the number of ambiguities at cell $(i, j)$. Further, $t_{\mathrm{ij}}$ and $l_{\mathrm{ij}}$ stand for the analysis wind components at cell $(i, j)$ across and along the scatterometer swath orientation, respectively. Similarly, $t_{i j, k}^{(o)}$ and $l_{i j, k}^{(o)}$ stand for the observed ambiguous wind components, and $\sigma_{t}$ and $\sigma_{l}$ for the estimated standard deviations of the errors in the scatterometer wind components. The parameter $\lambda$ is an empirical parameter that weights the different ambiguities; a $\lambda$ value of 4 provides optimal separation between multiple solutions. The parameter $p_{k}$ is the apriori probability of ambiguity number $k$ being the correct solution. Its value is derived by the inversion and quality control procedure [Stoffelen and Anderson, 1997b; Portabella and Stoffelen, 2004].

Assuming that the errors of the background wind field are Gaussian, the background term $J_{b}$ is written as [Vogelzang, 2007] 


\begin{tabular}{|c|c|c|c|c|}
\hline 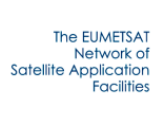 & Z NWP SAF & $\begin{array}{l}\text { On mesoscale analysis and } \\
\text { ASCAT ambiguity removal }\end{array}$ & $\begin{array}{l}\text { Doc ID } \\
\text { Version } \\
\text { Date }\end{array}$ & $\begin{array}{l}: \text { NWPSAF-KN-VS-014 } \\
: 1.0 \\
: 05-08-2015\end{array}$ \\
\hline
\end{tabular}

$$
J_{b}=(\delta \mathbf{x})^{\mathrm{T}} B_{t, l}^{-1}(\delta \mathbf{x})
$$

where $B_{t, l}$ is a matrix of estimated background error covariances, defined in terms of the wind components $t$ and $l$. The superscript T indicates the transpose of a vector or matrix. The inversion of $B_{t, l}$ may be time consuming since it is large and not diagonal. In the numerical implementation, the background cost function is transformed to the spatial frequency domain with a Fourier transformation $\mathbf{F}$ and is expressed in terms of stream function and velocity potential increments, $\delta \hat{\chi}$ and $\delta \hat{\psi}$, using an inverse Helmholz transformation $\mathbf{H}^{-\mathbf{1}}$. Introducing $\delta \boldsymbol{\xi}=\mathbf{H}^{-\mathbf{1}} \mathbf{F} \delta \mathbf{x}$ as the transformed state vector, the cost function reads [Vogelzang, 2007]

$$
J_{b}=(\delta \xi)^{\mathrm{T}} B_{\hat{\chi}, \hat{\psi}}^{-1}(\delta \xi)
$$

Now the background error covariance matrix $B_{\hat{\chi}, \hat{\psi}}$ is symmetric, positive definite, and (approximately) block diagonal. It can be factorized into error variances $\sum$ and error correlations $\mathbf{C}$ by

$$
B_{\hat{\chi}, \hat{\psi}}=\sum \mathbf{C} \sum
$$

with

$$
\begin{aligned}
& \sum=\left(\begin{array}{cc}
\sum_{\hat{\chi}} & 0 \\
0 & \sum_{\hat{\psi}}
\end{array}\right) \\
& \mathbf{C}=\left(\begin{array}{cc}
\mathbf{C}_{\hat{\chi} \hat{\chi}} & 0 \\
0 & \mathbf{C}_{\hat{\psi} \hat{\psi}}
\end{array}\right)
\end{aligned}
$$

Here $\sum_{\hat{\chi}}$ and $\sum_{\hat{\psi}}$ are diagonal with the error standard deviations $\sigma_{\hat{\chi}}$ and $\sigma_{\hat{\psi}}$ as components, while $\mathbf{C}_{\hat{\chi} \hat{\chi}}$ and $\mathbf{C}_{\hat{\psi} \hat{\psi}}$ contain the autocorrelations $\rho_{\hat{\chi} \hat{\chi}}$ and $\rho_{\hat{\psi} \hat{\psi}}$, respectively.

The current 2DVAR in AWDP uses fixed observation and background errors, i.e., $\sigma_{t}=\sigma_{l}=1.8$ $\mathrm{m} / \mathrm{s} ; \sigma_{\hat{\chi}}=\sigma_{\hat{\psi}}=2.0 \mathrm{~m} / \mathrm{s}$. It also uses homogeneous and isotropic error correlations described by Gaussian structure functions. These key parameters are revisited in order to improve the ASCAT wind ambiguity removal.

We note that a salient difference between 2DVAR and the objective in variational data assimilation. The objective of $2 \mathrm{DVAR}$ is to produce an analysis on the observed spatial scales, while in 3D- or 4D-var the aim is to initialize the degrees of freedom in the model state, i.e., to produce an analysis on the scales allowed by the forecast model in use. 


\begin{tabular}{|c|c|c|c|c|}
\hline 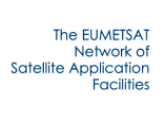 & Z NWP SAF & $\begin{array}{l}\text { On mesoscale analysis and } \\
\text { ASCAT ambiguity removal }\end{array}$ & $\begin{array}{l}\text { Doc ID } \\
\text { Version } \\
\text { Date }\end{array}$ & $\begin{array}{l}: \text { NWPSAF-KN-VS-014 } \\
: 1.0 \\
: 05-08-2015\end{array}$ \\
\hline
\end{tabular}

\section{Estimation of ECMWF background and ASCAT observation errors}

Given a set of collocated measurements from three different wind sources, and choosing one source as calibration reference, it is possible to estimate the random measurement errors as well as the relative calibration coefficients for each wind data source independently [Stoffelen, 1998; Vogelzang et al., 2011]. In this section, the triple collocation (TC) method is applied to estimate the ECMWF and ASCAT errors for different wind quality categories, as defined by the MLE and SE parameters.

\subsection{Defining wind quality categories}

This section summarizes the use of two ASCAT-derived parameters, MLE and SE, for classifying wind quality. The ASCAT MLE or wind inversion residual can be expressed as:

$$
\operatorname{MLE}=\frac{1}{3} \sum_{i=1}^{3}\left(z_{\mathrm{m} i}-z_{\mathrm{s} i}\right)^{2}
$$

following a Bayesian retrieval [Stoffelen and Portabella, 2006], where $z_{\mathrm{m} i}=\left(\sigma_{\mathrm{m} i}^{0}\right)^{0.625}$ is the backscatter measurement of the $i$ th beam in z-space, and $z_{s i}=\left(\sigma_{s i}^{0}\right)^{0.625}$ is the backscatter simulated through the geophysical model function (GMF), i.e., CMOD5n [Verhoef et al., 2008], using the solution wind vector as input. The MLE equals the minimum distance between the measured triplet and the surface constructed by the GMF in the 3-D measurement space, a double-folded cone surface [Stoffelen and Anderson, 1997b]. In general, the triplets are located close to the GMF surface, which leads to low MLE values and good quality wind retrievals. Occasionally, a large inconsistency between the triplets and the GMF is induced by other geophysical conditions than a WVC-mean wind, resulting in large MLE values. A MLE sign is defined by Portabella et al. [2012] particularly for ASCAT, in order to better segregate different sea surface geophysical conditions. Triplets located inside the GMF cone surface are assigned with a positive MLE value, while those located outside the cone surface are assigned with a negative MLE value. Lin et al. [2015a] show that large positive MLE values correspond to high wind variability conditions, and as a result, in retrieved winds of reduced quality. 


\begin{tabular}{|c|c|c|c|c|}
\hline 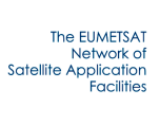 & Z NWP SAF & $\begin{array}{l}\text { On mesoscale analysis and } \\
\text { ASCAT ambiguity removal }\end{array}$ & $\begin{array}{l}\text { Doc ID } \\
\text { Version } \\
\text { Date }\end{array}$ & $\begin{array}{l}: \text { NWPSAF-KN-VS-014 } \\
: 1.0 \\
: 05-08-2015\end{array}$ \\
\hline
\end{tabular}

The singularity exponent, derived from an image processing technique called singularity analysis, depicts the degree of local regularity (spatial gradient) around a given point $\mathbf{x}$ for a given scalar signal $s$. It roughly behaves as [Turiel et al., 2008; Pont et al., 2011; Lin et al., 2014],

$$
\mathrm{SE}(\mathrm{X}) \square \frac{\log |\nabla s|(\mathrm{X})}{\log r}
$$

where the gradient $|\nabla s|(\mathrm{x})$ is estimated in a circle with radius $r$. In the numerical implementation, $|\nabla s|(\mathrm{x})$ is calculated within a $3 \times 3 \mathrm{WVC}$ window centered on the analyzed point. Negative SE values correspond to a less regular behavior of the function, while positive SE values indicate a more regular behavior. Note that SE uses a context of $9 \mathrm{WVCs}$ and therefore provides a statistically more accurate value than the MLE, which are single WVC values derived from 3 independent backscatter measurements.

While MLE is sensitive to intra-WVC variability, SE is sensitive to inter-WVC variability. However, as shown by [Lin et al., 2015a], both parameters are sensitive to increased local wind variability and are rather complementary. Consequently, it makes sense to combine them in order to better discriminate between reduced-quality and good quality winds. Fig. 1(a) illustrates the VRMS difference between ASCAT and ECMWF winds as a function of SE and MLE. It shows that ASCAT and ECMWF wind discrepancies increase as SE decreases and/or MLE increases. A similar trend is found when the VRMS difference between ASCAT and buoy winds is computed (see Fig. 1b). As discussed in [Lin et al., 2015a], larger discrepancies between ASCAT, buoy, and ECMWF winds correspond to areas of larger wind variability. In [Lin et al., 2015b], a novel TC analysis approach is used to evaluate the quality of areas with large wind variability conditions (according to MLE and SE) in comparison to the stable wind areas, and it is found that the wind quality is indeed degraded with increased wind variability, notably for ECMWF winds. In this study, the collocated data set is separated into 6 categories according to SE and MLE, as shown in Fig. 2, in order to obtain a finer relationship between MLE/SE and wind quality which can be used in a more general context, such as the use of adaptive ASCAT and background (ECMWF) errors in the AWDP 2DVAR scheme. Note that the SE thresholds in Fig. 2 are chosen such that the SD of the ASCAT wind difference w.r.t. MARS buoys of WVCs with $\operatorname{SE} \in\left(S_{1}, S_{2}\right]$ is similar to those of WVCs with MLE $\in\left[M_{1}, M_{2}\right)$. 


\begin{tabular}{|c|c|c|c|c|}
\hline 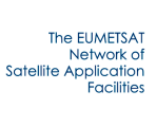 & ₹ NWP SAF & $\begin{array}{l}\text { On mesoscale analysis and } \\
\text { ASCAT ambiguity removal }\end{array}$ & $\begin{array}{l}\text { Doc ID } \\
\text { Version } \\
\text { Date }\end{array}$ & $\begin{array}{l}: \text { NWPSAF-KN-VS-014 } \\
: 1.0 \\
: 05-08-2015\end{array}$ \\
\hline
\end{tabular}
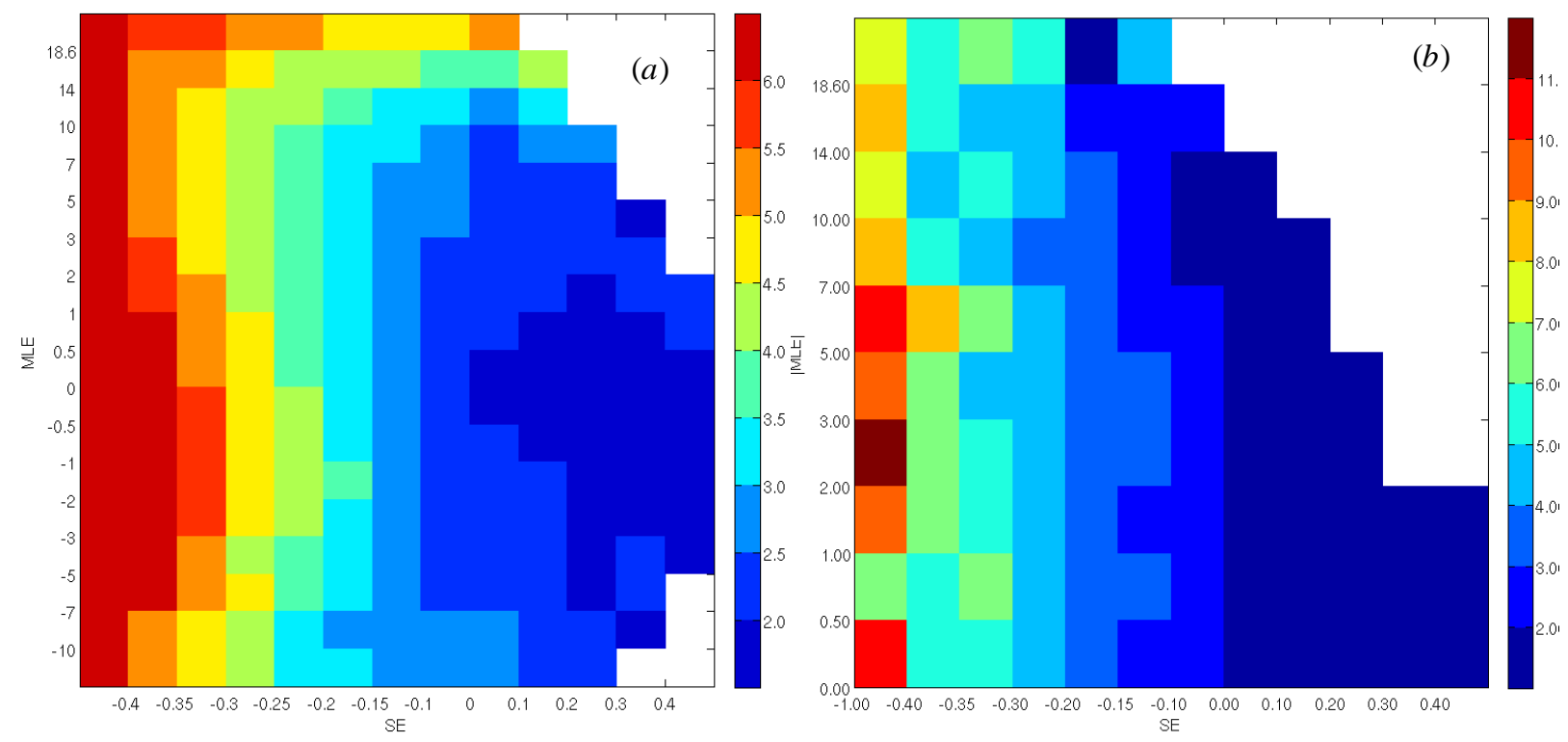

Fig. 1 The VRMS difference between ASCAT and (a) ECMWF, (b) MARS buoy winds as a function of SE and MLE. Due to the lack of ASCAT and buoy collocations, the MLE sign is ignored in the right panel.

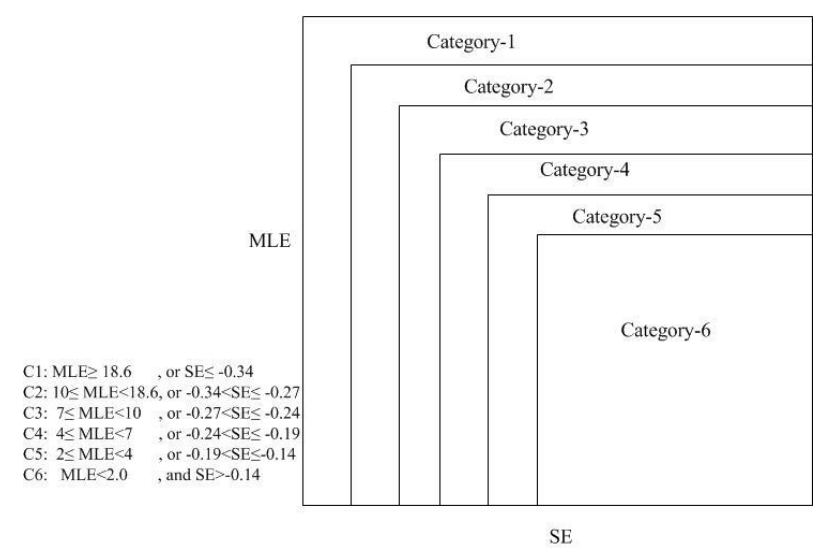

Fig. 2 The triple collocation data set is separated into 6 categories for the sake of TC analysis.

\subsection{TC method}

The random errors of wind data from three collocated sources (buoy, ASCAT, and ECMWF forecasts, in this case) can be quantitatively evaluated from the triple collocation method [Stoffelen, 1998]. Given three measurement systems $W_{i}, i=1,2$, 3, which represent buoy, scatterometer and ECMWF respectively, the measurements are approximated by the following linear expression,

$$
W_{i}=a_{i} w+b_{i}+\delta_{i}
$$




\begin{tabular}{|c|c|c|c|c|}
\hline 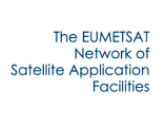 & Z NWP SAF & $\begin{array}{l}\text { On mesoscale analysis and } \\
\text { ASCAT ambiguity removal }\end{array}$ & $\begin{array}{l}\text { Doc ID } \\
\text { Version } \\
\text { Date }\end{array}$ & $\begin{array}{l}: \text { NWPSAF-KN-VS-014 } \\
: 1.0 \\
: 05-08-2015\end{array}$ \\
\hline
\end{tabular}

where $w$ is the common quantity in this study, i.e., the true wind at certain spatial scale. Further, $a_{i}$ and $b_{i}$ stand for the scaling and bias calibration coefficients, respectively, and $\delta_{i}$ for the random measurement error. $\delta_{i}$ is assumed to be unbiased, and its variance does not change with $w$. These assumptions hold well for the $u$ and $v$ wind components [Stoffelen, 1998].

The observation errors are assumed to be uncorrelated with $w$, such that $\left\langle\delta_{i} w\right\rangle=0$. Buoy and scatterometer winds resolve smaller scales than ECMWF, and the variance common to these smaller scales, $r^{2}=\left\langle\delta_{1} \delta_{2}\right\rangle$, is part of the observation errors $\delta_{1}$ and $\delta_{2}$. By definition $r^{2}$ is the correlated part of the spatial representativeness errors of $W_{1}$ and $W_{2}$. Furthermore, since $W_{3}$ does not include these smaller scales, its observation error $\delta_{3}$ is independent of $\delta_{1}$ and $\delta_{2}$, such that $\left\langle\delta_{i} \delta_{3}\right\rangle=0$ $(i=1,2)$. In summary, the wind component errors of the different systems are all assumed to be uncorrelated, except for the representative error [Stoffelen, 1998].

Now the calibration coefficients are related with the mixed second-order moments as follows,

$$
\left\{\begin{array}{l}
M_{12}=a_{1} a_{2}\left\langle w^{2}\right\rangle+r^{2} \\
M_{13}=a_{1} a_{3}\left\langle w^{2}\right\rangle \\
M_{23}=a_{2} a_{3}\left\langle w^{2}\right\rangle
\end{array}\right.
$$

where $M_{i j}=\left\langle W_{i} W_{j}\right\rangle(i, j=1,2,3)$ stands for the mixed second-order moment of system $i$ and $j$. If the wind system ref (where ref value can be 1,2, or 3) is chosen as calibration reference, then the other two calibration coefficients are given by respectively,

$$
\begin{aligned}
& \left\{\begin{array}{l}
a_{2}=\frac{M_{23}}{M_{31}} \\
a_{3}=\frac{M_{23}}{M_{12}-r^{2}}
\end{array} \quad\left(r e f=1, \text { i.e, } a_{1}=1\right)\right. \\
& \left\{\begin{array}{l}
a_{1}=\frac{M_{13}}{M_{23}} \\
a_{3}=\frac{M_{13}}{M_{12}-r^{2}}
\end{array} \quad\left(\text { ref }=2, \text { i.e, } a_{2}=1\right)\right. \\
& \left\{\begin{array}{l}
a_{1}=\frac{M_{12}-r^{2}}{M_{23}} \\
a_{2}=\frac{M_{12}-r^{2}}{M_{13}}
\end{array} \quad\left(r e f=3, \text { i.e, } a_{3}=1\right)\right.
\end{aligned}
$$

The bias correction coefficients $b_{i}$ are given by,

$$
b_{i}=M_{i}-a_{i} M_{r e f} \quad(i \neq r e f)
$$

where $M_{i}$ stands for the first order moment of the $i^{\text {th }}$ system. The calibrated data sets are created by 


$$
W_{i}^{\prime}=\frac{1}{a_{i}}\left(W_{i}-b_{i}\right)
$$

The TC analysis is implemented using an iterative approach. The calibrated data sets (i.e., $W_{2}^{\prime}$ and $\left.W_{3}^{\prime}\right)$ are used to estimate the new calibration coefficients, until these parameters converge. Normally, the convergence is met within six iterations. After calibration, the error variances estimated on ECMWF scale for each wind system are given by

$$
\left\langle\delta_{i}^{2}\right\rangle=M_{i i}-\varepsilon^{2}
$$

The quantity $\varepsilon^{2}$ has several different expressions, e.g., $\varepsilon^{2}=M_{12}-r^{2}=M_{23}=M_{13}$ and denotes the common true variance in the three measurement systems. Note that to obtain the error variances on the ASCAT scale, $r^{2}$ has to be subtracted from the above buoy and scatterometer error variances, and added to the ECMWF error variance. Finally, the statistical accuracy of the error variances is given by [Vogelzang et al., 2011b]

$$
\operatorname{var}\left(\left\langle\delta_{i}^{2}\right\rangle\right)=\frac{2\left\langle\delta_{i}^{2}\right\rangle^{2}+\left\langle\delta_{i}^{2}\right\rangle\left\langle\delta_{j}^{2}\right\rangle}{N}
$$

where $N$ is the number of collocations, and $j=\bmod (i, 3)+1$.

In case of high variability conditions, there are quite a few ambiguity removal errors of the scatterometer winds against buoy winds. One could mitigate such errors for TC analysis in the following statistically consistent way:

1) Allow each of the three wind vectors in a collocation triplet to have two ambiguities $180^{\circ}$ apart, leading to 8 different combinations of which 4 are independent (i.e., $\left\{W_{1}, W_{2}, W_{3} ;-W_{1}, W_{2}, W_{3}\right.$; $\left.W_{1},-W_{2}, W_{3} ;-W_{1},-W_{2}, W_{3}\right\}$; the other 4 differ by an overall minus sign);

2) Calculate the center of gravity for each of the four ambiguous triplets;

3) Calculate the distance of each of the ambiguous triplet winds to the center of gravity and find the maximum distance $d_{\max }^{i}$. Fig. 3 illustrates the process of steps 2) and 3) for one of the four ambiguous triplets;

4) Select the ambiguous triplet that has the smallest maximum distance to its center of gravity. In this way, one loses some physical consistency, but retains statistical consistency. Therefore particularly the larger error estimates will be somewhat optimistic, but can be interpreted in a relative manner. This procedure is called mitigation of ambiguity removal errors (MARE), and is applied in the TC analysis on all 6 wind categories defined in Section 4.1. 


\begin{tabular}{|c|c|c|c|c|}
\hline 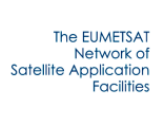 & Z NWP SAF & $\begin{array}{l}\text { On mesoscale analysis and } \\
\text { ASCAT ambiguity removal }\end{array}$ & $\begin{array}{l}\text { Doc ID } \\
\text { Version } \\
\text { Date }\end{array}$ & $\begin{array}{l}: \text { NWPSAF-KN-VS-014 } \\
: 1.0 \\
: 05-08-2015\end{array}$ \\
\hline
\end{tabular}

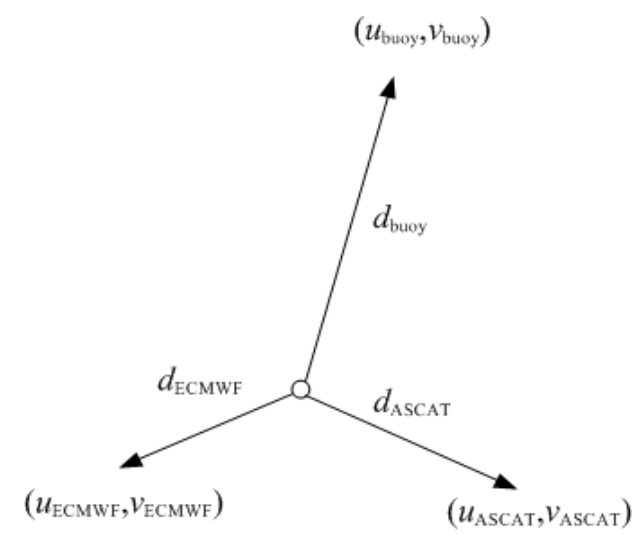

Fig. 3 The distance of each of the ambiguous triplet winds to the center of gravity. The maximum distance of the $i^{\text {th }}$ triplet is given by $d_{\max }^{i}=\left\{d_{\text {buoy }}^{i}, d_{\mathrm{ASCAT}}^{i}, d_{\mathrm{ECMWF}}^{\mathrm{i}}\right\}$

\subsection{TC results}

According to [Vogelzang et al., 2011b], the representativeness error $\left(r^{2}\right)$ is estimated by integrating the difference between ASCAT and ECMWF wind spectra from the minimum scatterometer scale of $25 \mathrm{~km}$ to the maximum ECMWF deficit scale of $800 \mathrm{~km}$. In [Vogelzang et al., 2015], cumulative variance is calculated as a function of spatial scale, and the representativeness error is found to be given by the difference in cumulative variance of scatterometer and ECMWF wind components at a scale of $200 \mathrm{~km}$. Anyway, to compute accurate wind spectra or cumulative variances one needs to process representative series of wind data of sufficient length. However, poor-quality (high variability) wind regions, categories 1 to 4 , are generally very localized, thus an alternative method to compute $r^{2}$ is required.

A strong assumption of the TC method is that once convergence is achieved, the three wind sources have to be very well intercalibrated. This can only be achieved with consistent calibration coefficients, $r^{2}$, and measurement error values. In [Lin et al., 2015b], $r^{2}$ is inferred to directly influence the scaling coefficient for ASCAT and buoys, with too high (low) $r^{2}$ value resulting in too low (high) scaling value. And from Eq. (15) we infer that too low (high) scaling values results in more positive (negative) bias. Consequently, a practical way of estimating $r^{2}$ is to repeat the TC analysis for different $r^{2}$ values until a close intercalibration of the different wind sources is achieved, in particular, the $r^{2}$ value which determines a bias close to zero (i.e., best fit) for both the calibrated buoy and ASCAT winds (w.r.t. ECMWF winds) is considered as the best estimated spatial representativeness error. To simplify the search of the 'best' $r^{2}$ estimate, the ratio of $r_{u}^{2}$ and $r_{v}^{2}$ is assumed to be same than that computed for stable wind conditions using the classical wind 


\begin{tabular}{|c|c|c|c|c|}
\hline $\begin{array}{l}\text { The EUMEESAT } \\
\text { Networof } \\
\text { Satellitie Appolicalion } \\
\text { Facilities }\end{array}$ & Z NWP SAF & $\begin{array}{l}\text { On mesoscale analysis and } \\
\text { ASCAT ambiguity removal }\end{array}$ & $\begin{array}{l}\text { Doc ID } \\
\text { Version } \\
\text { Date }\end{array}$ & $\begin{array}{l}: \text { NWPSAF-KN-VS-014 } \\
: 1.0 \\
: 05-08-2015\end{array}$ \\
\hline
\end{tabular}

spectra based TC method (i.e., $r_{v}^{2} / r_{u}^{2}=1.5$ ) [Vogelzang et al., 2011b], such that there is only one unknown parameter in the search of the optimal $r^{2}$ value. Table 1 presents the representativeness errors for the 6 wind categories using triple collocations with MARS buoy winds. By using the proposed $r^{2}$ estimation algorithm, the resulting values for stable winds (the higher categories) are similar to those presented by Vogelzang et al. [2011b] $\left(r_{u}^{2}=0.63, r_{v}^{2}=1.00\right)$, therefore validating the proposed algorithm.

Table 1: The spatial representativeness errors $r_{u}^{2}$ (and $r_{v}^{2}$ ) of the triple collocations at different wind categories.

\begin{tabular}{|c|c|c|c|c|c|c|}
\hline Category & 1 & 2 & 3 & 4 & 5 & 6 \\
\hline$r_{u}^{2}$ & 1.6 & 1.1 & 0.7 & 0.7 & 0.64 & 0.56 \\
\hline$r_{v}^{2}$ & 2.4 & 1.7 & 1.1 & 1.1 & 0.96 & 0.84 \\
\hline
\end{tabular}

Fig. 4 shows the estimated SD errors (on ECMWF scale) for each wind system and for each of the six wind categories. In general, the errors of all the wind sources increase as MLE increases and/or SE decreases. Comparing the three wind sources, ASCAT SD errors are the smallest over all categories, followed by buoy (except for category 6, the most stable wind category) and ECMWF. The SD errors from Fig. 4 can be used as O/B errors in 2DVAR by simply projecting the MLE and SE values into the categories of Fig. 2 under the assumptions that $\sigma_{l} \approx \sigma_{v}$ and $\sigma_{t} \approx \sigma_{u}$. These assumptions hold well for the equatorial and subtropical regions which comprise most of the ASCAT data. Note that in 2DVAR we aim for a close fit to the ASCAT observations to favour optimal ambiguity selection, which means that the weight of the ASCAT observations may be somewhat increased with respect to the ratio of 2.0/1.8.

To illustrate spatial background error structure, Fig. 5(a) depicts one view of ECMWF background error SD derived from ASCAT L2 data while Fig. 5(b) shows the collocated ECMWF Ensemble Data Assimilation (EDA) background error SD. Since the ASCAT acquisition was at around 09:00 UTC, the EDA data at 09:00 UTC are only interpolated spatially into ASCAT WVCs. Although there is some resemblance between ASCAT-derived background error and the EDA error, notably in the left swath, the former shows much more details about the error structure than the latter.

Fig. 5(c) shows the mean EDA background errors (the markers) and the corresponding spreads (standard deviation, see the error bars) for the six wind categories. For the sake of comparison, $x$ axis shows the ASCAT-derived background errors. As expected, the correlation coefficients 


\begin{tabular}{|c|c|c|c|c|}
\hline 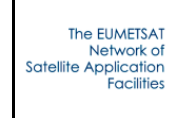 & ¿ NWP SAF & $\begin{array}{l}\text { On mesoscale analysis and } \\
\text { ASCAT ambiguity removal }\end{array}$ & $\begin{array}{l}\text { Doc ID } \\
\text { Version } \\
\text { Date }\end{array}$ & $\begin{array}{l}: \text { NWPSAF-KN-VS-014 } \\
: 1.0 \\
: 05-08-2015\end{array}$ \\
\hline
\end{tabular}

between EDA and ASCAT-derived background errors are generally low. Nevertheless, the mean EDA error increases as more background error is detected by ASCAT. Besides, the mean EDA error over the tropics is higher than that of the extratropics, as well as the correlation between EDA and ASCAT-derived background errors. Since EDA uses a limited set of ensembles, one expects the variation in the B spatial error structures to be smooth, while ASCAT provides B error estimates on a 25-km scale. A more advanced spatial EDA validation would thus be of interest.

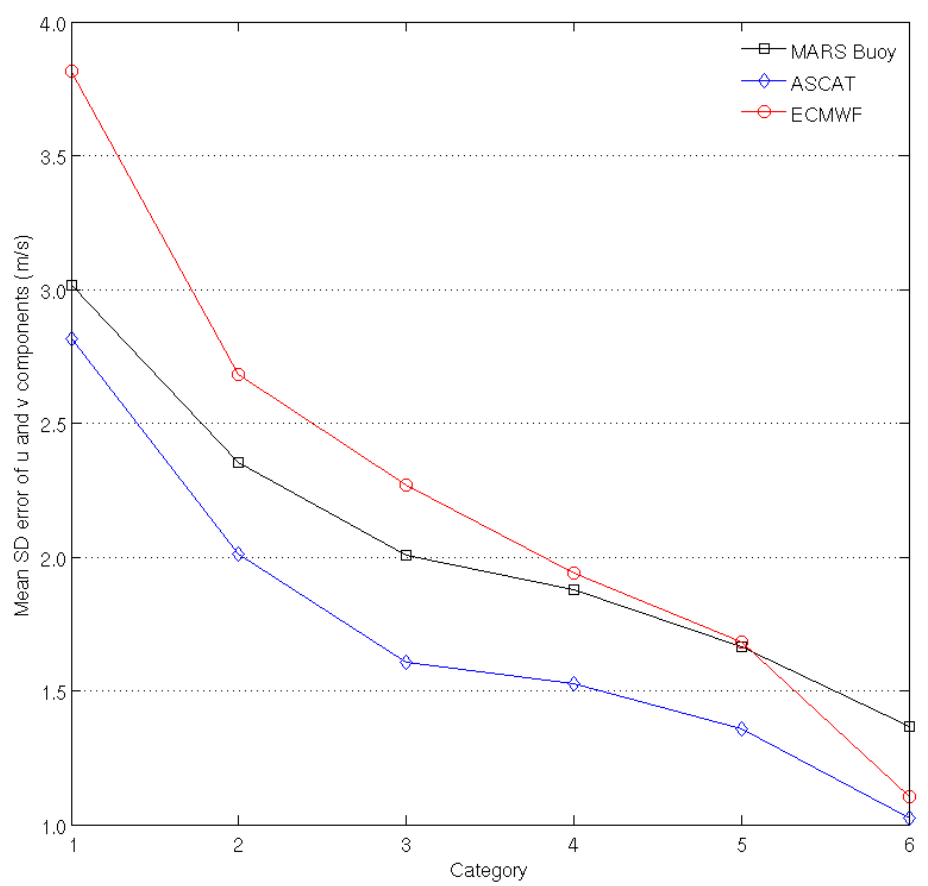

Fig. 4 Mean SD of the random errors of wind $u$ and $v$ components on ECMWF scale for buoy, ASCAT and ECMWF. 


\begin{tabular}{|c|c|c|c|c|}
\hline 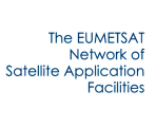 & ₹ NWP SAF & $\begin{array}{l}\text { On mesoscale analysis and } \\
\text { ASCAT ambiguity removal }\end{array}$ & $\begin{array}{l}\text { Doc ID } \\
\text { Version } \\
\text { Date }\end{array}$ & $\begin{array}{l}: \text { NWPSAF-KN-VS-014 } \\
: 1.0 \\
: 05-08-2015\end{array}$ \\
\hline
\end{tabular}
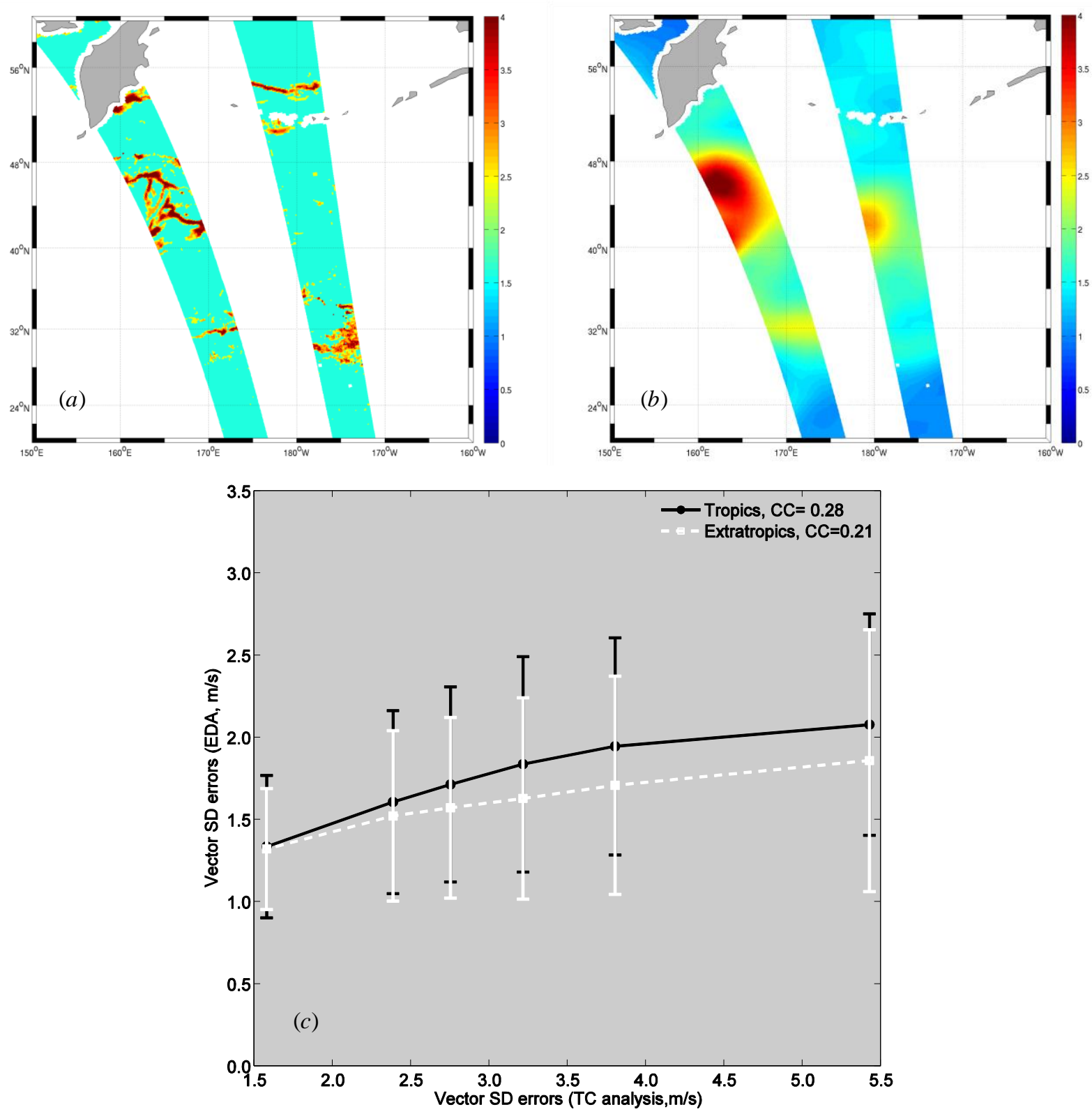

Fig. 5 (a) ECMWF SD error estimated from ASCAT L2 data, Jan $3^{\text {rd }}$ 2013, around UTC 09:00; $(b)$ The collocated EDA background error (see the color bar); (c) The mean EDA errors and the standard deviations for the six predefined wind categories. The black-dotted line shows the statistics over the tropics, and the white line shows the statistics over the extratropics. 


\begin{tabular}{|c|c|c|c|c|}
\hline 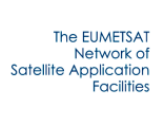 & Z NWP SAF & $\begin{array}{l}\text { On mesoscale analysis and } \\
\text { ASCAT ambiguity removal }\end{array}$ & $\begin{array}{l}\text { Doc ID } \\
\text { Version } \\
\text { Date }\end{array}$ & $\begin{array}{l}: \text { NWPSAF-KN-VS-014 } \\
: 1.0 \\
: 05-08-2015\end{array}$ \\
\hline
\end{tabular}

\section{ECMWF Background Error Structure Functions}

The autocorrelations (structure functions) of the stream function and the velocity potential in the spatial domain ( $\rho_{\chi \chi}$ and $\rho_{\psi \psi}$ ) are related to the autocorrelations of the longitudinal and transversal wind components $\left(\rho_{t t}\right.$ and $\left.\rho_{l l}\right)$ [Daley, 1991; Vogelzang and Stoffelen, 2011a] by

$$
\begin{aligned}
& \rho_{\chi \chi}(r)=1+\frac{S(r)+R(r)}{2 \alpha_{\chi}} \\
& \rho_{\psi \psi}(r)=1+\frac{S(r)-R(r)}{2 \alpha_{\psi}}
\end{aligned}
$$

where

$$
\begin{aligned}
& S(r)=\int_{0}^{r} \mathrm{~d} s \frac{J(s)}{s} \\
& R(r)=\int_{0}^{r} \mathrm{~d} s \cdot s I(s) \\
& J(r)=\int_{0}^{r} \mathrm{~d} s \cdot s\left[\rho_{t t}(s)+\rho_{l l}(s)\right] \\
& I(r)=\int_{r}^{\infty} \mathrm{d} s \frac{1}{s}\left[\rho_{t t}(s)-\rho_{l l}(s)\right]
\end{aligned}
$$

The parameters $\alpha_{\chi}$ and $\alpha_{\psi}$ are determined by the requirement that the structure functions approach zero as $r$ goes to infinity as

$$
\begin{aligned}
& \alpha_{\chi}=-\frac{1}{2}[S(\infty)+R(\infty)] \\
& \alpha_{\psi}=-\frac{1}{2}[S(\infty)-R(\infty)]
\end{aligned}
$$

The length scales $L_{\chi}$ and $L_{\psi}$ are given by

$$
\begin{gathered}
L_{\chi}^{2}=\left.\frac{\rho_{\chi \chi}(r)}{\nabla^{2} \rho_{\chi \chi}(r)}\right|_{r=0}=-\frac{2 \alpha_{\chi}}{1+I(0)} \\
L_{\psi}^{2}=\left.\frac{\rho_{\psi \psi}(r)}{\nabla^{2} \rho_{\psi \psi}(r)}\right|_{r=0}=-\frac{2 \alpha_{\psi}}{1-I(0)}
\end{gathered}
$$

The divergence-to-rotation ratio $v^{2}$ reads

$$
v^{2}=\frac{1}{2}[1+I(0)]
$$




\begin{tabular}{|c|c|c|c|c|}
\hline 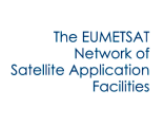 & Z NWP SAF & $\begin{array}{l}\text { On mesoscale analysis and } \\
\text { ASCAT ambiguity removal }\end{array}$ & $\begin{array}{l}\text { Doc ID } \\
\text { Version } \\
\text { Date }\end{array}$ & $\begin{array}{l}: \text { NWPSAF-KN-VS-014 } \\
: 1.0 \\
: 05-08-2015\end{array}$ \\
\hline
\end{tabular}

When the observation errors are uncorrelated, the background error correlation equals the correlated differences between observations and background (O-B). Marseille et al. [2013] provide an extended analysis of ASCAT O and ECMWF B spatial error structures. Therefore, the background error structure function can be easily empirically estimated from the operational ASCAT L2 data in a numerical way. However, the observed autocorrelations do not go to zero for large distances, due to the existence of climate zones and the finite size of the earth. In order to let the structure functions go to zero with vanishing derivative for large distances, it is necessary to apply a cut-off function for $\rho_{t t}(r)$ and $\rho_{l l}(r)$ such that $J(r)=0$ for large $r$ [Vogelzang and Stoffelen, 2011a].

Fig. 6 shows the structure functions $\rho_{\chi \chi}$ (red dashed line) and $\rho_{\psi \psi}$ (black dashed line) estimated from one month of ASCAT 12.5-km wind product (April 2009). The default Gaussian structure functions, currently used in the operational 2DVAR scheme, with different length scales are also presented as a reference. It shows the numerical structure functions are much broader than the Gaussian structure functions. In addition, the numerical $\rho_{\psi \psi}$ is broader than $\rho_{\chi \chi}$, as indicated by the higher value of $L_{\psi}$ in the legend. Since the spatial structure functions act as spatial filtering functions in meteorological analysis, one may expect smoother analyses result from broader background error structure functions. Moreover, in case of dense observation coverage at high weight, such as from ASCAT, overfitting of the broad structure functions may occur, even though its shape is generally more appropriate. Note also that the current 2DVAR scheme in AWDP assumes fixed divergence-to-rotation ratio of 0.5 in the Tropics and of 0.2 in the Extratropics; while the empirically derived $v^{2}$ value is about 0.62 , which is larger than the current setting particularly over the Extratropics. 


\begin{tabular}{|c|c|c|c|c|}
\hline 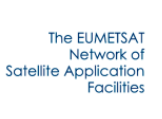 & ₹ NWP SAF & $\begin{array}{l}\text { On mesoscale analysis and } \\
\text { ASCAT ambiguity removal }\end{array}$ & $\begin{array}{l}\text { Doc ID } \\
\text { Version } \\
\text { Date }\end{array}$ & $\begin{array}{l}: \text { NWPSAF-KN-VS-014 } \\
: 1.0 \\
: 05-08-2015\end{array}$ \\
\hline
\end{tabular}

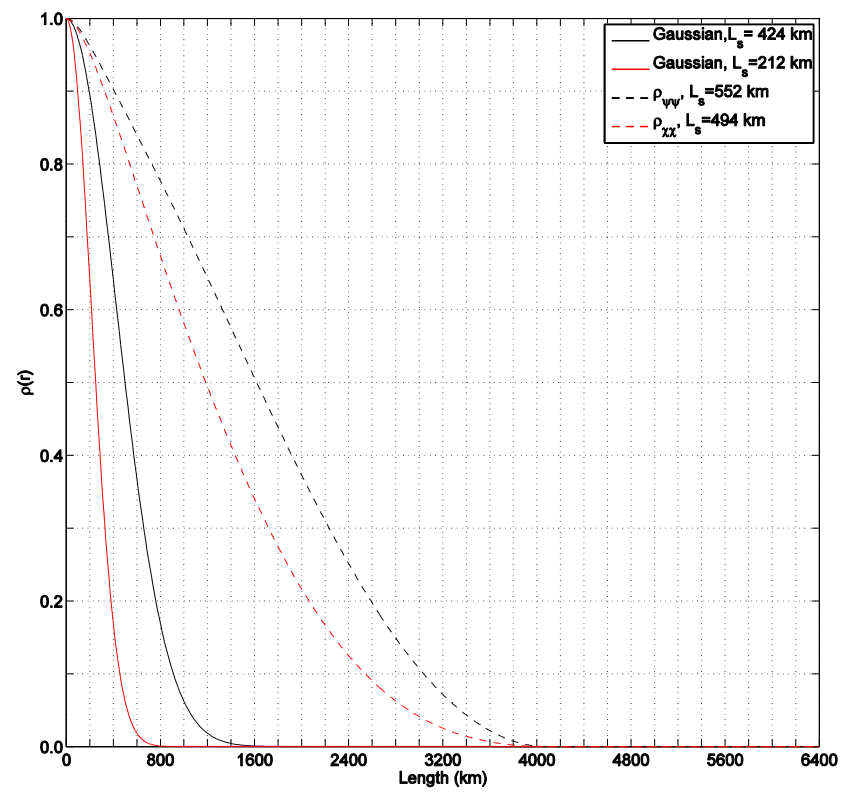

Fig. 6 Numerical structure functions (dashed lines) calculated from autocorrelations over the entire region with a simple brick-wall cutoff, i.e. setting $\rho_{t t}(r)$ and $\rho_{l l}(r)$ to be zero for large $r$ that corresponds to a negative $J(r)$ value, and Gaussian analytical structure functions (solid lines) currently used in 2DVAR. 


\begin{tabular}{|c|c|c|c|c|}
\hline 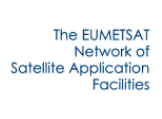 & Z NWP SAF & $\begin{array}{l}\text { On mesoscale analysis and } \\
\text { ASCAT ambiguity removal }\end{array}$ & $\begin{array}{l}\text { Doc ID } \\
\text { Version } \\
\text { Date }\end{array}$ & $\begin{array}{l}: \text { NWPSAF-KN-VS-014 } \\
: 1.0 \\
: 05-08-2015\end{array}$ \\
\hline
\end{tabular}

\section{Improved 2DVAR}

In this section, the 2DVAR scheme with the following different parameter settings is tested in order to look for an optimal configuration for ASCAT ambiguity removal:

$>$ Test 1: AWDP default setting, i.e., Gaussian structure function (GSF) and fixed Observation/Background (O/B) errors;

$>$ Test 2: GSF and the flexible O/B errors estimated in section 4;

$>$ Test 3: The numerical structure function (NSF) computed in section 5, and fixed O/B errors;

$>$ Test 4: NSF and flexible O/B errors;

Vogelzang [2014] shows that GSF yields test results closest the analytical results for a rather large batch grid size $(\geqslant 50 \mathrm{~km})$, therefore the 2DVAR grid size of $100 \mathrm{~km}$ is chosen for GSF. The NSF performs best for a 2DVAR grid size of $25 \mathrm{~km}$. Since NSF is much broader than GSF, one needs to increase the 2DVAR grid dimension, and in turn, increase the computation time remarkably. A trade-off between the 2DVAR performance and the computation time is considered, and thus the 2DVAR grid size of $50 \mathrm{~km}$ is chosen for NSF. Table 2 summarizes the 2DVAR settings for the above four tests. The larger the 2DVAR grid is, the longer the 2DVAR computation time. In general, NSF takes six times as much computation time as GSF. Therefore, only half a year of data (March-August 2009) is reprocessed for the above four tests.

Next, the AR results of several typical cases are illustrated and discussed in section 6.1. Then a general validation using buoy winds as reference is presented in section 6.2.

Table 2: The settings of 2DVAR key parameters for different tests. The divergence-to-rotation ratio is shown in the last column.

\begin{tabular}{|c|c|c|c|c|c|c|}
\hline & $\begin{array}{c}\text { Structure } \\
\text { function }\end{array}$ & $\begin{array}{c}\text { O/B errors } \\
(\mathrm{m} / \mathrm{s})\end{array}$ & $\begin{array}{c}\text { 2DVAR grid } \\
\text { dimension }\end{array}$ & $\begin{array}{c}\text { 2DVAR grid } \\
\text { size }(\mathrm{km})\end{array}$ & $\begin{array}{c}\text { 2DVAR grid } \\
\text { extension }\end{array}$ & $v^{2}$ \\
\hline Test 1 & GSF, Fig. 6 & $\sigma_{\mathrm{O}}=1.8$ & 100 & 10 & $\begin{array}{c}0.2(\mid \text { Lat } \mid<20) \\
0.5(\mid \text { Lat } \mid>20)\end{array}$ \\
\hline Test_2 & GSF, Fig. 6 & Fig. 4 & $32 \times 32$ & 100 & 10 & $\begin{array}{c}0.2(\mid \text { Lat } \mid<20) \\
0.5(\mid \text { Lat } \mid>20)\end{array}$ \\
\hline Test_3 & NSF, Fig. 6 & $\sigma_{\mathrm{O}}=1.8$ & $252 \times 32$ & 50 & 120 & 0.62 \\
\hline Test_4 & NSF, Fig. 6 & Fig. 4 & $252 \times 264$ & 50 & 120 & 0.62 \\
\hline
\end{tabular}

\subsection{Test cases}

$>$ Cyclone 


\begin{tabular}{|c|c|c|c|c|}
\hline 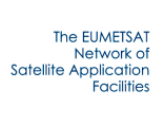 & Z NWP SAF & $\begin{array}{l}\text { On mesoscale analysis and } \\
\text { ASCAT ambiguity removal }\end{array}$ & $\begin{array}{l}\text { Doc ID } \\
\text { Version } \\
\text { Date }\end{array}$ & $\begin{array}{l}: \text { NWPSAF-KN-VS-014 } \\
: 1.0 \\
: 05-08-2015\end{array}$ \\
\hline
\end{tabular}

Fig. 7(a) shows the ECMWF forecast wind field collocated with the ASCAT overpass on March $10^{\text {th }} 2009$, around 11:48 UTC. The ECMWF background low-pressure center is clearly mislocated with respect to that shown by the ASCAT wind ambiguities field (Fig. 7b), which latter corresponds well with the presence of heavy rain to the South of the low, as captured by TMI (Fig. 7d). Looking at the general structure of the flow, which can be easily inferred from the ASCAT wind ambiguity field in Fig. 7(b), one can clearly see that several ASCAT ambiguity-removed (or selected) wind vectors over the rectangular area in Fig. 7(c) are in fact wrong.
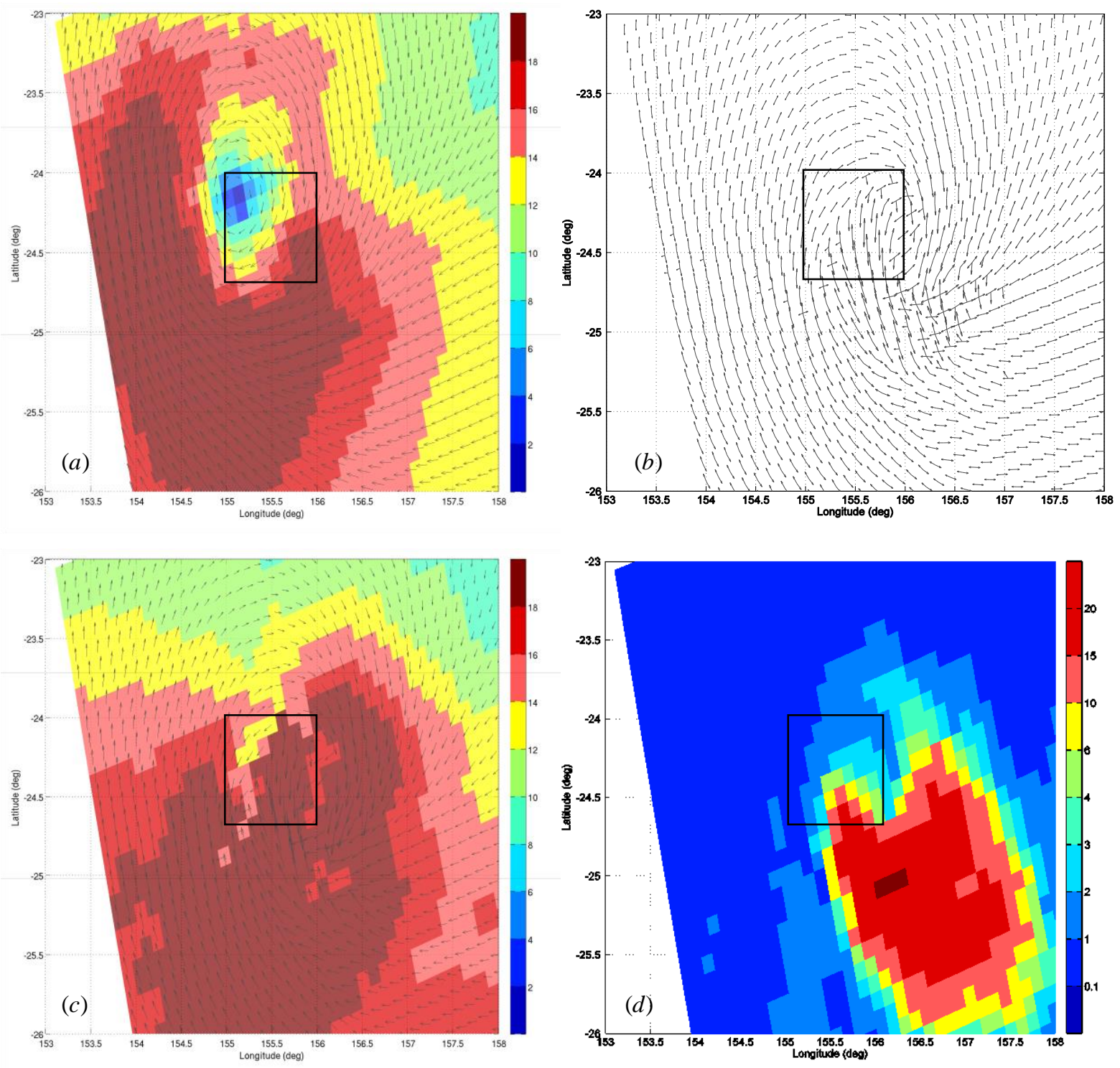

Fig. 7 (a) ECMWF forecast surface winds collocated with the ASCAT acquisition on March $10^{\text {th }} 2009$, around 11:48 UTC; (b) ASCAT-derived wind ambiguities; (c) ASCAT selected wind field processed with the operational AWDP settings (i.e., Test 1); (d) Collocated TMI rain distribution. 


\begin{tabular}{|c|c|c|c|c|}
\hline 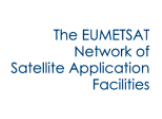 & Z NWP SAF & $\begin{array}{l}\text { On mesoscale analysis and } \\
\text { ASCAT ambiguity removal }\end{array}$ & $\begin{array}{l}\text { Doc ID } \\
\text { Version } \\
\text { Date }\end{array}$ & $\begin{array}{l}: \text { NWPSAF-KN-VS-014 } \\
: 1.0 \\
: 05-08-2015\end{array}$ \\
\hline
\end{tabular}

The imperfect AR in Fig. 7(c) is due to the fact that most of the ASCAT dual ambiguities (Fig. $7 b$ ) are generally aligned with the background field around the (mislocated) low-pressure center (Fig. 7a). Since ASCAT dual ambiguities are almost equally likely and 180 degrees apart, 2DVAR tends locally to the ECMWF background flow in these cases. Thus, the location of 2DVAR lowpressure center (Fig. 8a) is almost the same as that of ECMWF (Fig. 7a).

By using the flexible O/B errors derived in section 4, the resulting 2DVAR low-pressure center (Fig. $8 b$ ) is closer to that inferred from Fig. 7(b) than that derived with the nominal settings (Fig. $8 a$ ). However, the structure of the 2DVAR analysis flow remains similar to that of the background field (Fig. 7a). By incorporating NSF in 2DVAR, the resulting low-pressure center location and structure of the flow is further improved (i.e., streamlines become similar to those inferred from the ASCAT ambiguity field in Fig. 7b). In this case, however, the use of flexible O/B errors together with NSF (Fig. 8d) leads to a rather neutral impact on the 2DVAR field, as compared to the case of test 3 in Fig. $8 c$ (NSF and fixed O/B errors).
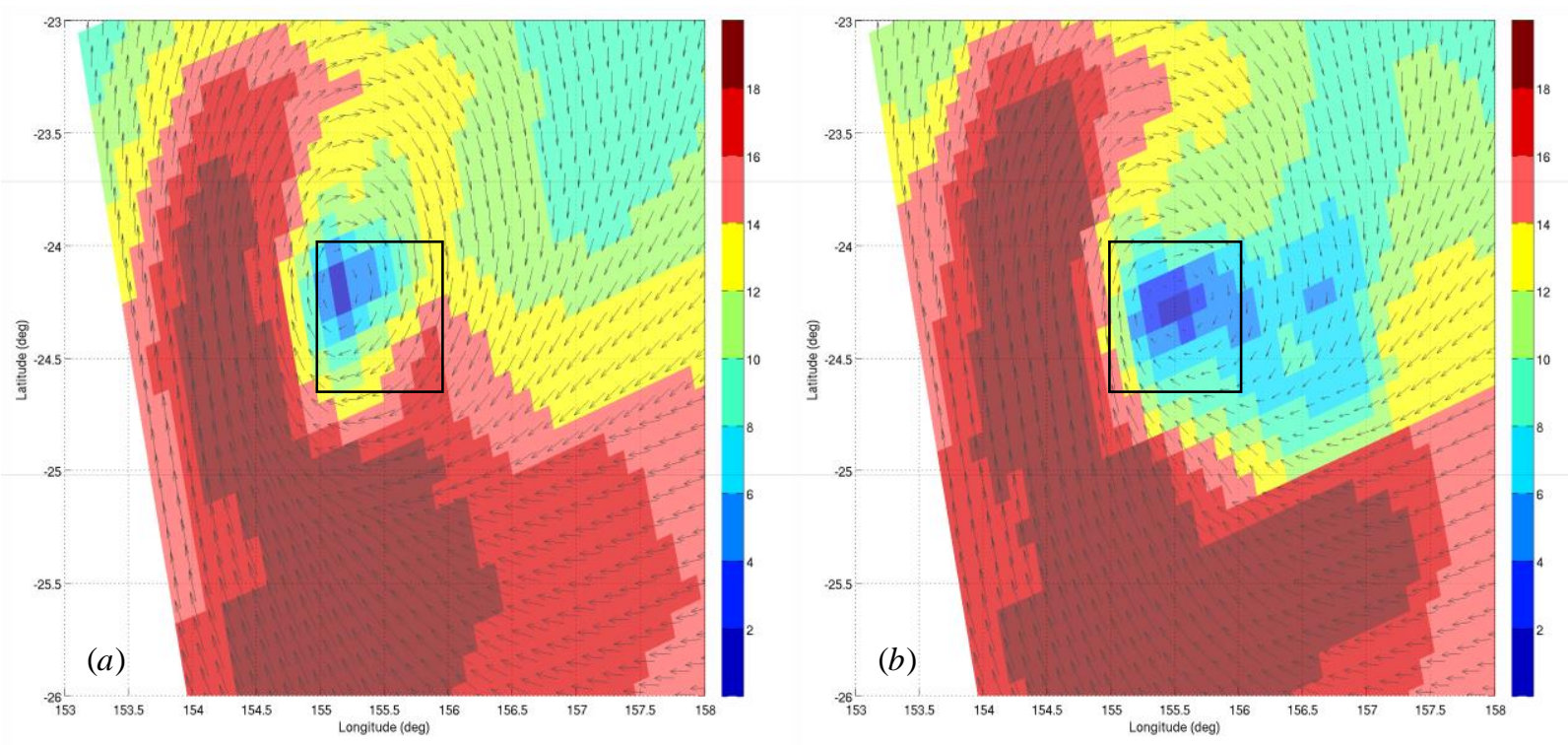


\begin{tabular}{|c|c|c|c|c|}
\hline 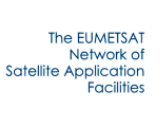 & ₹ NWP SAF & $\begin{array}{l}\text { On mesoscale analysis and } \\
\text { ASCAT ambiguity removal }\end{array}$ & $\begin{array}{l}\text { Doc ID } \\
\text { Version } \\
\text { Date }\end{array}$ & $\begin{array}{l}: \text { NWPSAF-KN-VS-014 } \\
: 1.0 \\
: 05-08-2015\end{array}$ \\
\hline
\end{tabular}
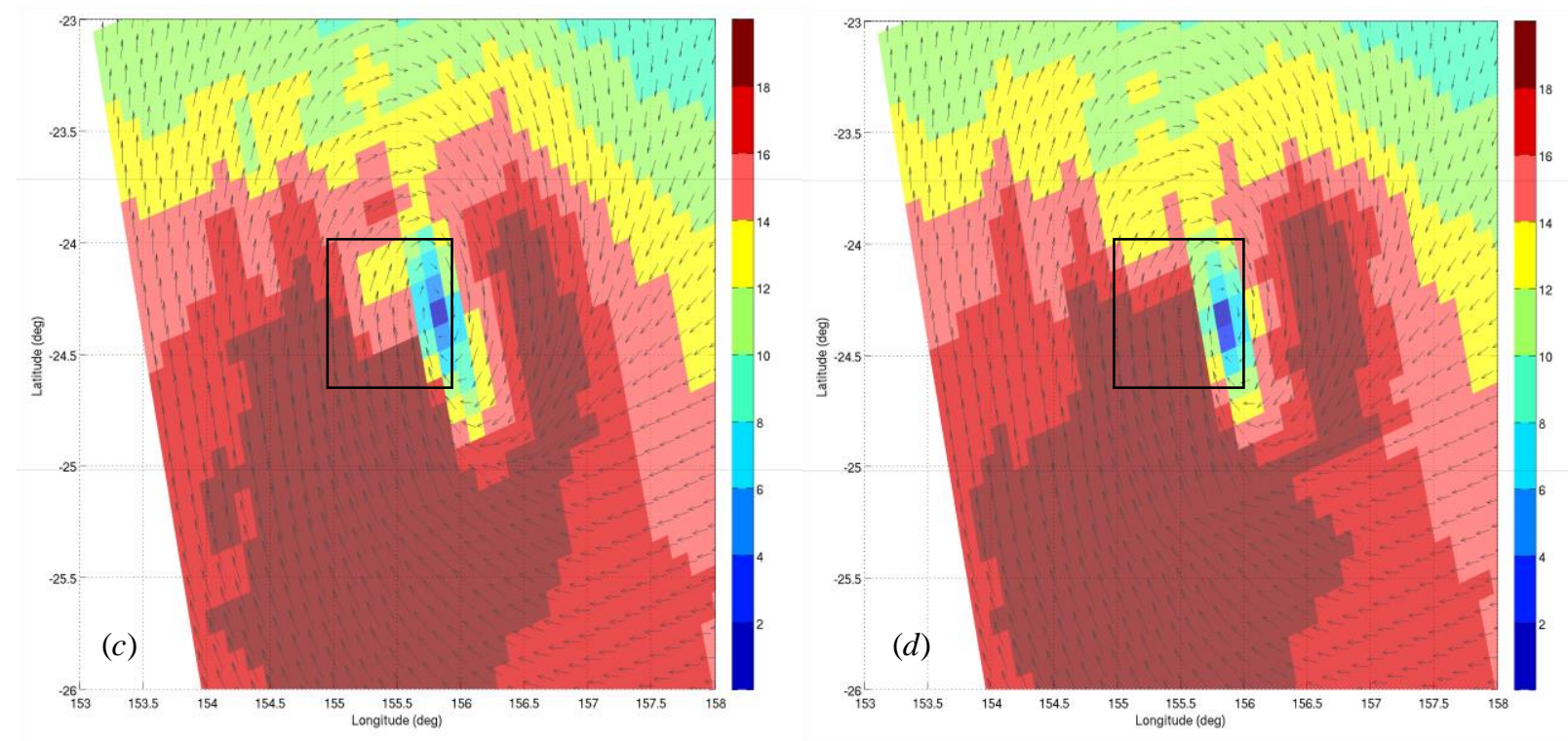

Fig. 8 2DVAR analysis wind field derived from: (a) AWDP default setting; (b) GSF and flexible O/B errors; (c) NSF and fixed O/B errors; $(d)$ NSF and flexible O/B errors.

Fig. 9 shows the ASCAT selected wind field superimposed with MLE values for the above four different settings. The use of either NSF or flexible O/B errors leads to smaller AR errors, i.e., both the structure of the mesocale system and center location are in better agreement with the ASCAT wind streamlines that may be inferred from the wind ambiguity field (Fig. 7c). The use of NSF has substantially larger positive impact on the ASCAT AR than the use of flexible O/B errors, in terms of both the 2DVAR analysis and the final wind selection. Regarding the wind vectors indicated with magenta dots, their MLE values are generally lower than those same WVCs in Fig. 9(a). For 3and/or 4-solution cases, this means that lower-rank wind solutions with higher probability of being the true winds are selected according to the new 2DVAR settings, which indicates that indeed the observational term has more weight with the new settings, notably with the NSF. 


\begin{tabular}{|c|c|c|c|c|}
\hline 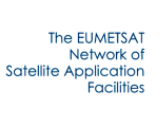 & ₹ NWP SAF & $\begin{array}{l}\text { On mesoscale analysis and } \\
\text { ASCAT ambiguity removal }\end{array}$ & $\begin{array}{l}\text { Doc ID } \\
\text { Version } \\
\text { Date }\end{array}$ & $\begin{array}{l}: \text { NWPSAF-KN-VS-014 } \\
: 1.0 \\
: 05-08-2015\end{array}$ \\
\hline
\end{tabular}
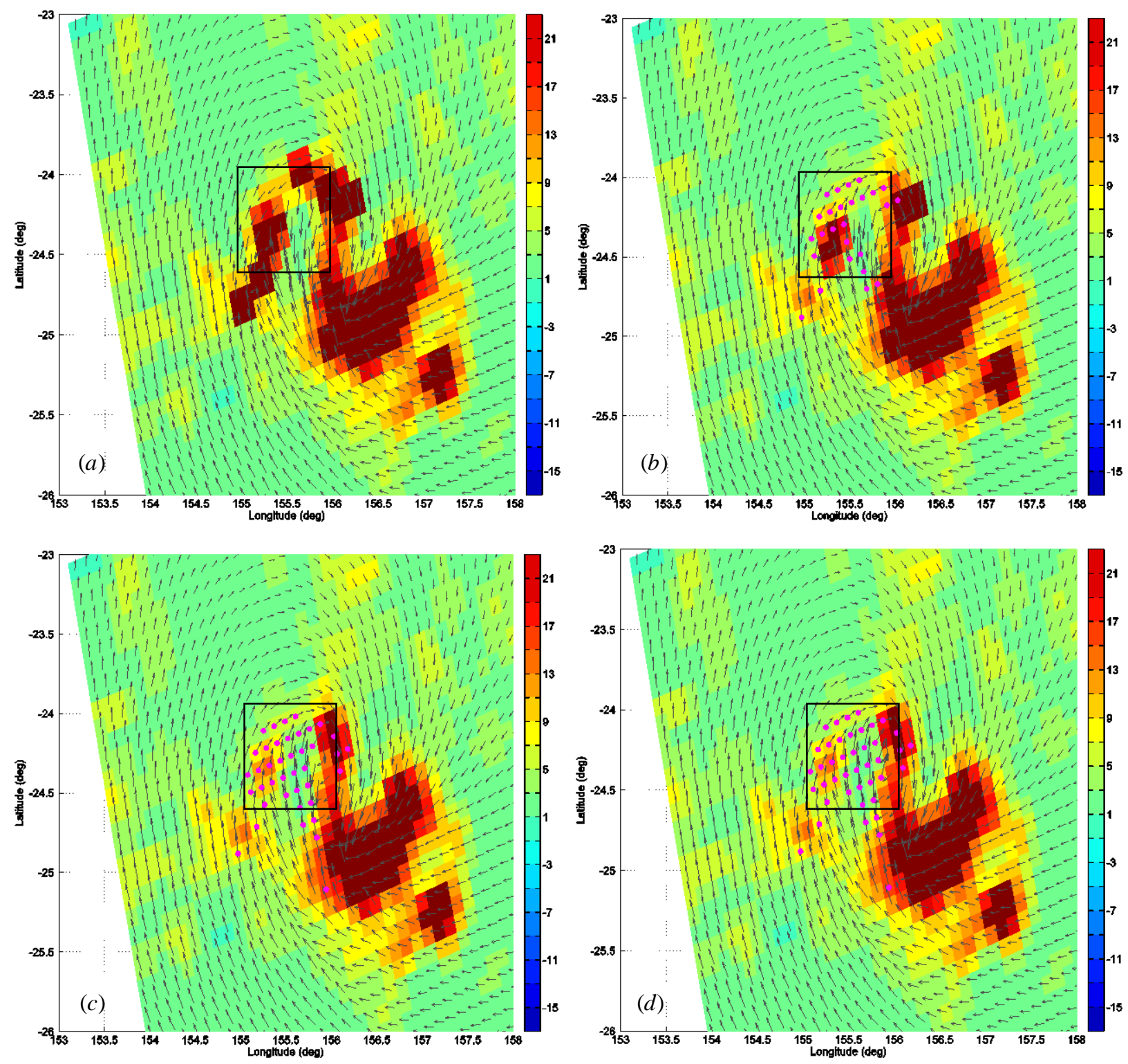

Fig. 9 ASCAT selected wind field superimposed with MLE values (see color bar) for: (a) AWDP default setting; (b) GSF and flexible O/B errors; (c) NSF and fixed O/B errors; (d) NSF and flexible O/B errors. The magenta dots in $(b)-(d)$ indicate the wind vectors changed w.r.t. those in $(a)$. Note that the wind field in $(a)$ is the same as that in Fig. $7(c)$.

\section{$>$ Frontal line}

Fig. 10 illustrates a typical frontal line error case. The ECMWF wind field (Fig. 10a) shows a clearly different flow than that of the ASCAT ambiguities (Fig. 10b), with an area of very low winds which is not depicted by ASCAT. The WVCs with three or four ambiguities in Fig. 10(b) are probably associated with the presence of rain and therefore of increased wind variability, as shown 


\begin{tabular}{|c|c|c|c|c|}
\hline 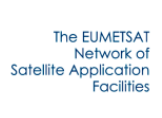 & Z NWP SAF & $\begin{array}{l}\text { On mesoscale analysis and } \\
\text { ASCAT ambiguity removal }\end{array}$ & $\begin{array}{l}\text { Doc ID } \\
\text { Version } \\
\text { Date }\end{array}$ & $\begin{array}{l}: \text { NWPSAF-KN-VS-014 } \\
: 1.0 \\
: 05-08-2015\end{array}$ \\
\hline
\end{tabular}

in Fig. 10(d). The ASCAT selected wind vectors over the rectangular region show a frontal line, as indicated by the singularity exponents (Fig. 10c).

Fig. 11 shows the 2DVAR analysis winds for the four different settings. The use of GSF and flexible O/B errors significantly changes the 2DVAR analysis, which shows the frontal line much to the south. The use of NSF (bottom plots) mainly resolves a thinner frontal line (as compare to Fig.11a) in the analysis field. Moreover, the analysis wind speeds over the rainy area for the NSF cases are lower and therefore more in agreement with ASCAT retrieved wind speeds (Fig.11b) than those in Fig. 11(a).

Fig. 12 shows the ASCAT selected winds superimposed with the corresponding MLE values for the four different 2DVAR settings. Since the new settings produce closer 2DVAR analysis to the observations as compared with the old settings, more low-rank solutions are selected by the AR procedure, corresponding to lower MLE values, particularly over the rain area. The MLE values (in Fig. 12) do not indicate the presence of a front line, but rather of a stable flow regime with continuous streamlines in the ambiguous winds. The combination of GSF and flexible O/B errors seems to produce the best analysis and wind selection in this case, putting the front line much to the south, where corresponding elevated MLE and wind variability occurs. Note that the ambiguity errors in the upper right corner remain in all 4 panels.
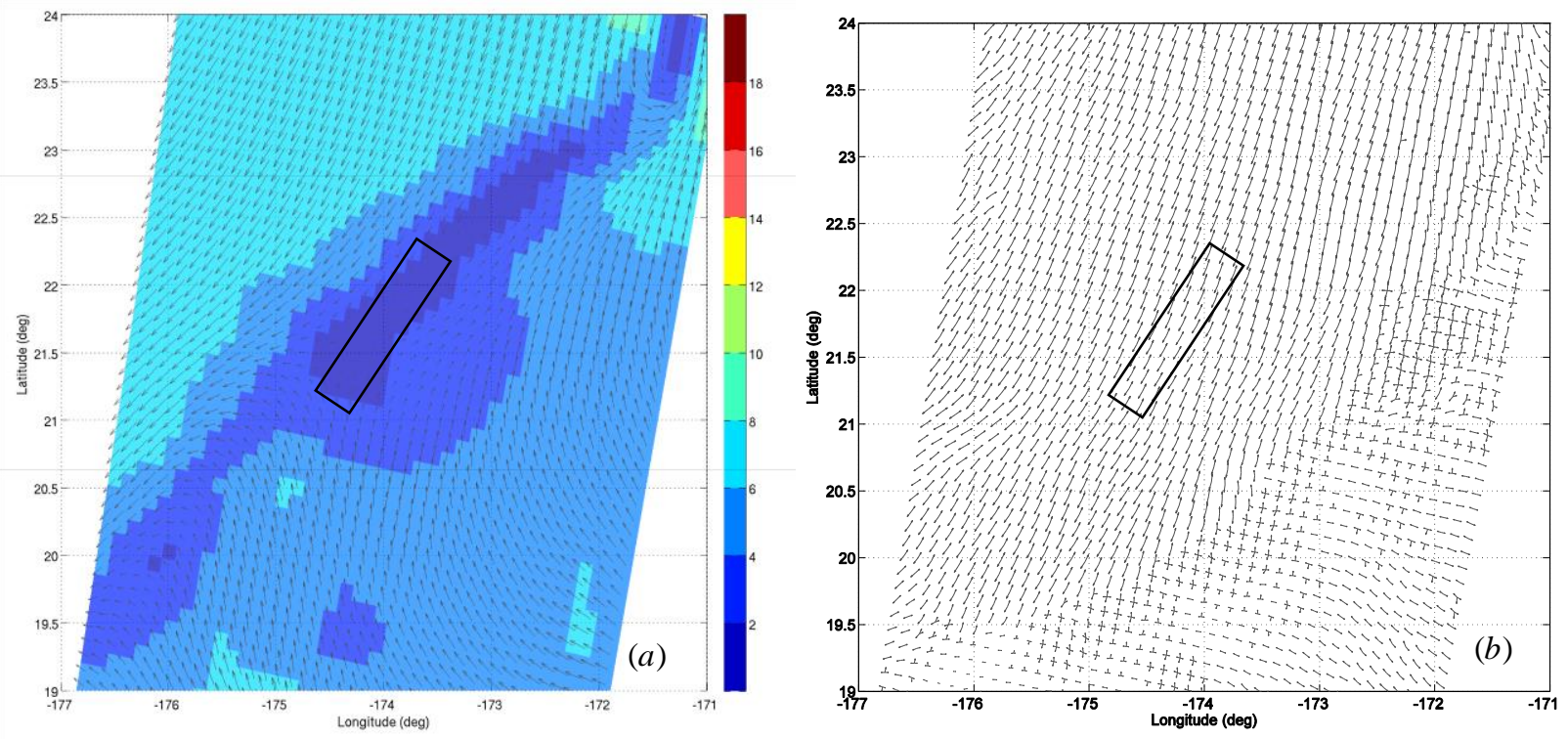


\begin{tabular}{|c|c|c|c|c|}
\hline 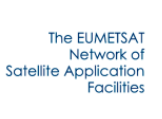 & ₹ NWP SAF & $\begin{array}{l}\text { On mesoscale analysis and } \\
\text { ASCAT ambiguity removal }\end{array}$ & $\begin{array}{l}\text { Doc ID } \\
\text { Version } \\
\text { Date }\end{array}$ & $\begin{array}{l}: \text { NWPSAF-KN-VS-014 } \\
: 1.0 \\
: 05-08-2015\end{array}$ \\
\hline
\end{tabular}
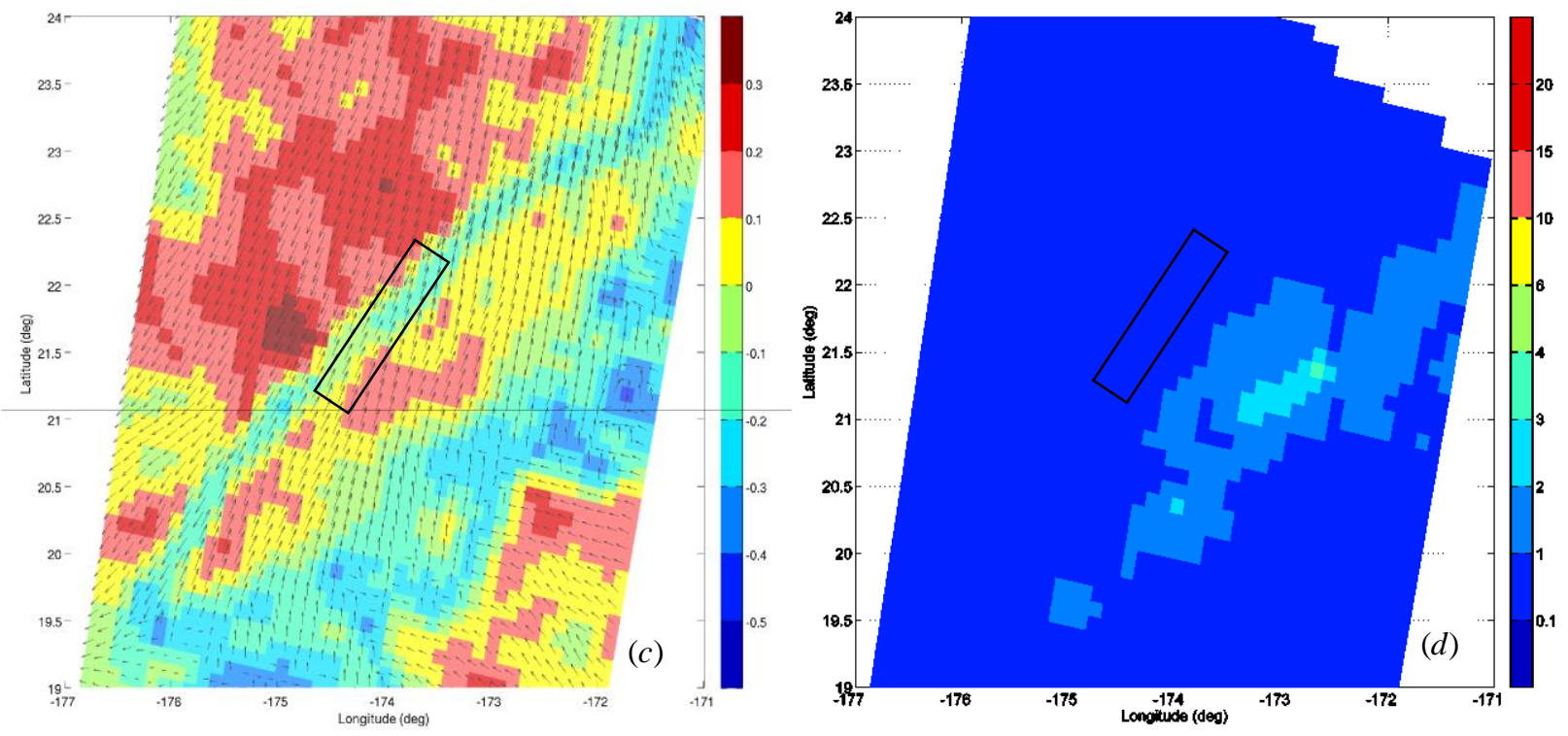

Fig. 10 (a) ECMWF forecasts collocated with the ASCAT acquisition on March 10 ${ }^{\text {th }}$ 2009, around 11:48 UTC; $(b)$ ASCAT wind ambiguities; (c) ASCAT selected wind field processed with the operational AWDP settings, superimposed with the singularity exponent values; $(d)$ Collocated TMI rain distribution. The color bars indicate wind speed $(a)$, singularity exponent $(c)$ and rain rate $(d)$ values.
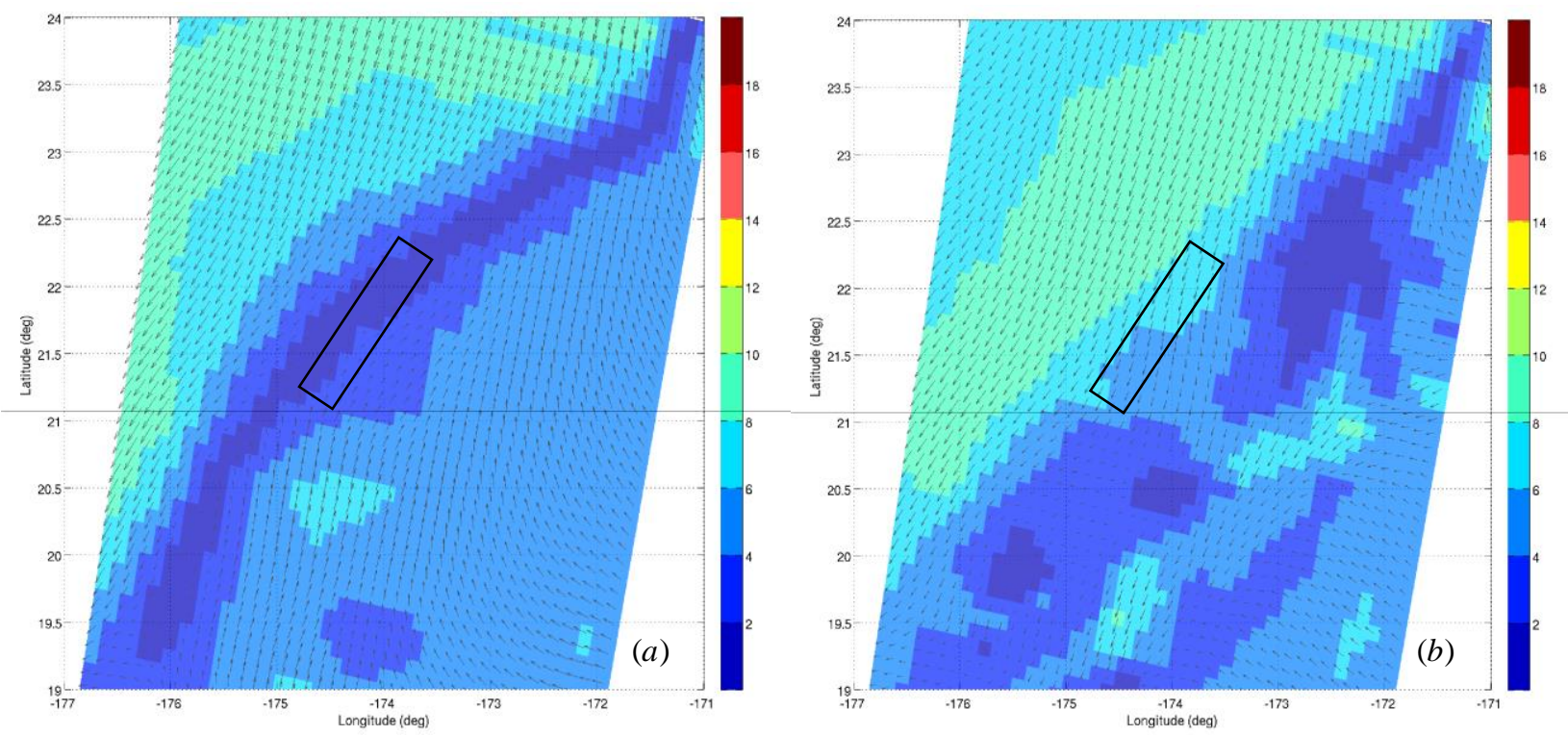


\begin{tabular}{|c|c|c|c|c|}
\hline 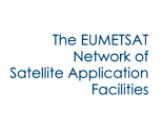 & NWW SAF & $\begin{array}{l}\text { On mesoscale analysis and } \\
\text { ASCAT ambiguity removal }\end{array}$ & $\begin{array}{l}\text { Doc ID } \\
\text { Version } \\
\text { Date }\end{array}$ & $\begin{array}{l}: \text { NWPSAF-KN-VS-014 } \\
: 1.0 \\
: 05-08-2015\end{array}$ \\
\hline
\end{tabular}
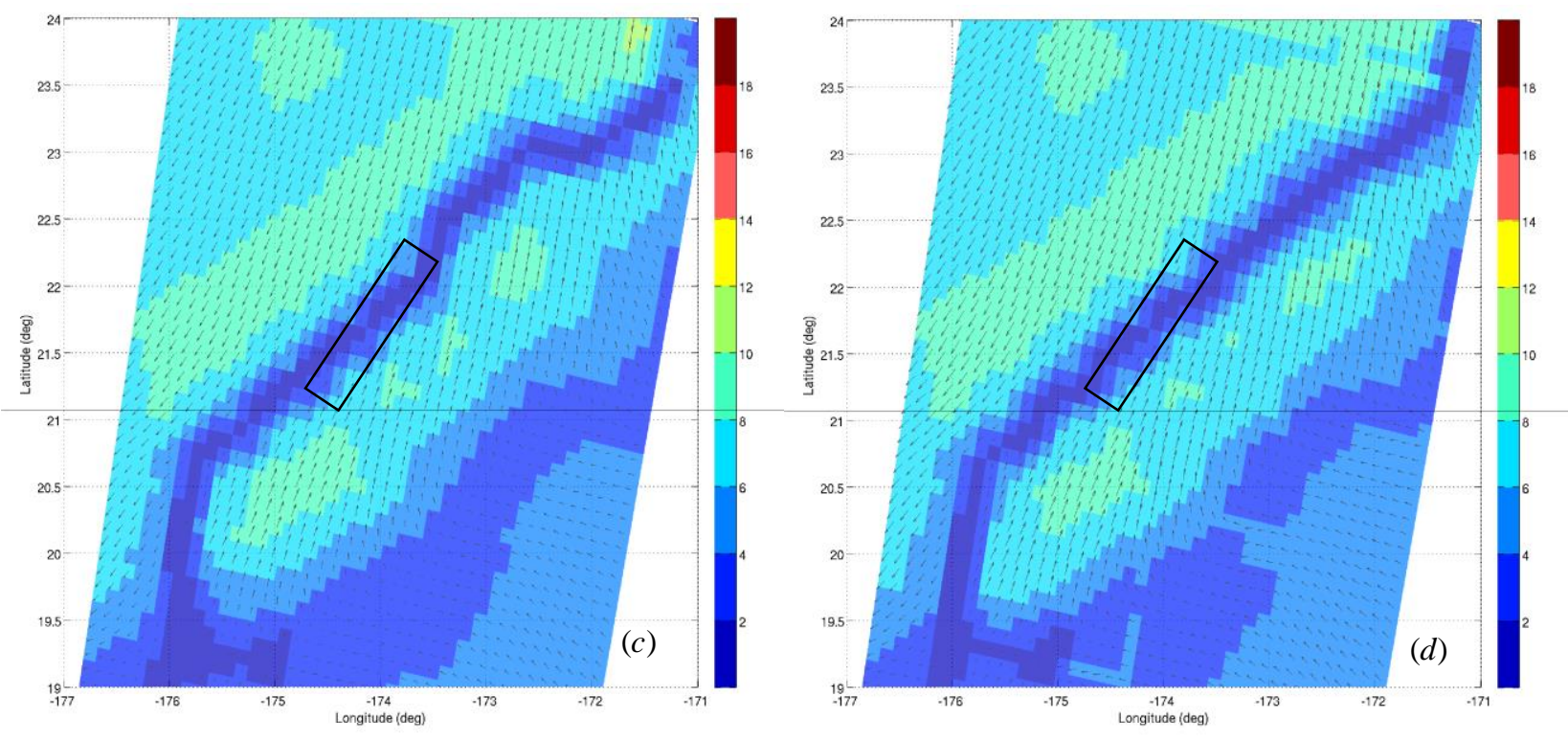

Fig. 11 2DVAR analys is wind field (see wind speed values indicated by the color bar) derived from: (a) AWDP default setting; (b) GSF and flexible O/B errors; (c) NSF and fixed O/B errors; (d) NSF and flexible O/B errors.
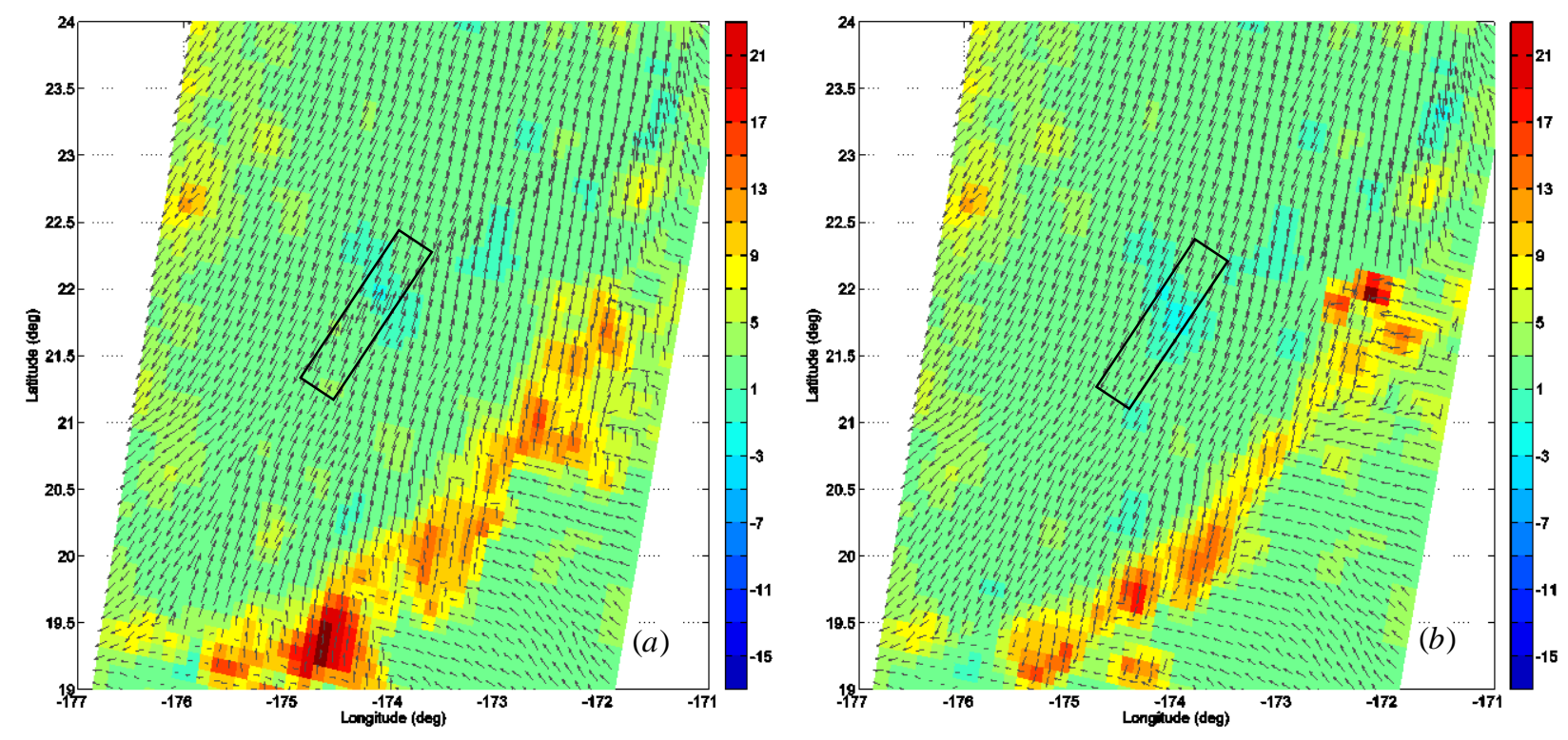


\begin{tabular}{|c|c|c|c|c|}
\hline 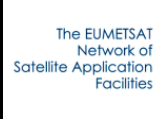 & $\angle$ NWP SAF & $\begin{array}{l}\text { On mesoscale analysis and } \\
\text { ASCAT ambiguity removal }\end{array}$ & $\begin{array}{l}\text { Doc ID } \\
\text { Version } \\
\text { Date }\end{array}$ & $\begin{array}{l}: \text { NWPSAF-KN-VS-014 } \\
: 1.0 \\
: 05-08-2015\end{array}$ \\
\hline
\end{tabular}
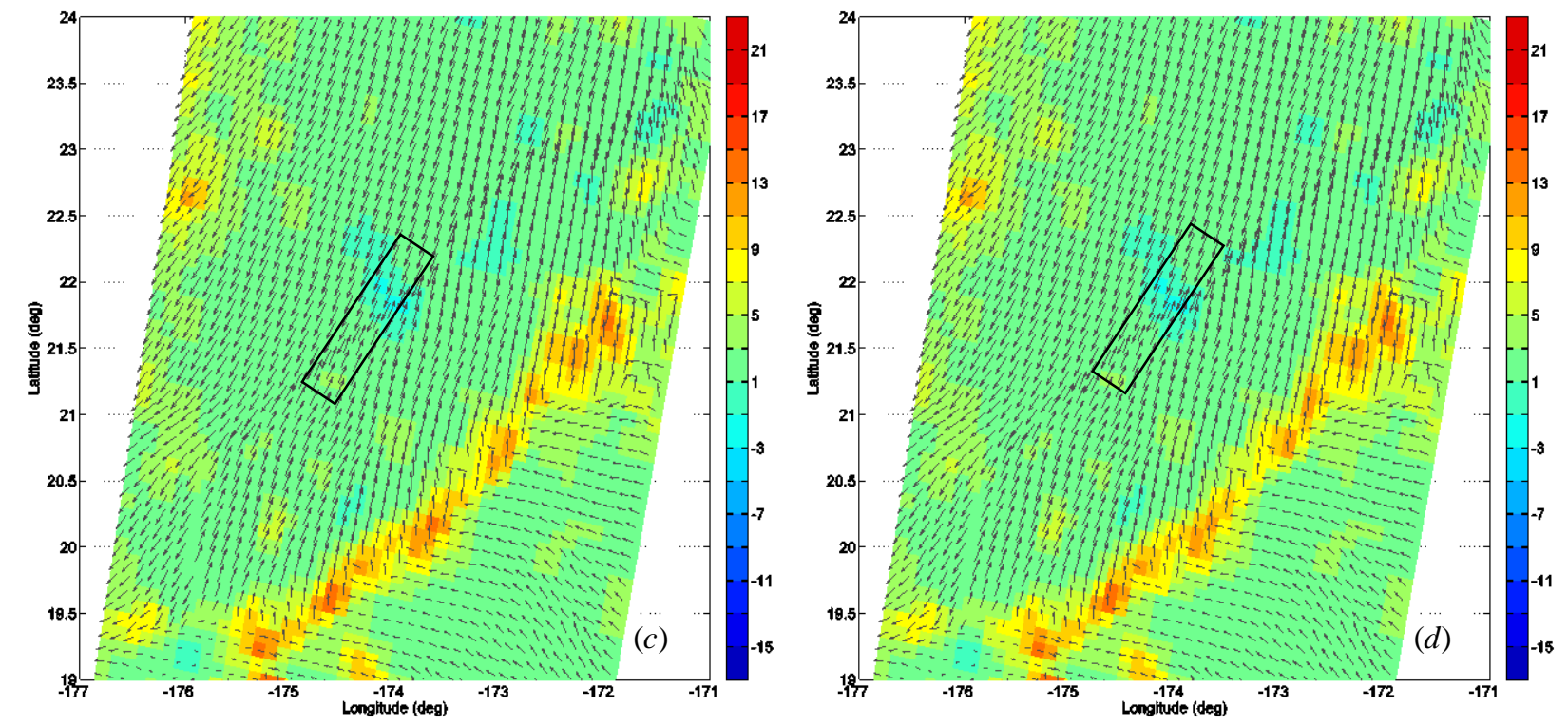

Fig. 12 ASCAT selected wind field superimposed with MLE values (see color bar) derived from: (a) AWDP default setting; (b) GSF and flexible O/B errors; (c) NSF and fixed O/B errors; (d) NSF and flexible O/B errors. Note that the ASCAT wind field in $(a)$ is the same as that in Fig. $10 c$.

\section{$>$ Frontal line}

Fig. 13 presents a particular case with linear divergent patterns retrieved by ASCAT, with erratic winds selected in the rectangular areas in Fig. 13(c). Over these rainy areas (see Fig. 13d), the ECMWF forecast winds (Fig. 13a) are almost across the sub-satellite track direction and almost perpendicular to the ASCAT-derived wind ambiguities (Fig. 13b). The 2DVAR analysis wind field derived with the default settings (Fig. 14a) is similar to that of the ECMWF background (Fig. 13a), i.e., with a similar wind direction pattern about 90 degrees apart from both ASCAT wind ambiguities (Fig. 13b) over the marked areas. Therefore, the wind selection over these areas becomes rather arbitrary, resulting in spurious wind divergence patterns, as shown in Fig. 13(c).

The use of GSF and flexible O/B errors (Fig. 14b) only modifies the analysis wind over the heavy rainy areas (around $\left[18.5^{\circ} \mathrm{S} 164^{\circ} \mathrm{W}\right]$ ), with respect to the nominal case (Fig. 14a) or the ECMWF background (Fig. 13a). Therefore, the ASCAT-selected wind field (Fig. 15b) shows spatially inconsistent wind patterns around the rectangular areas and more in particular close to the front line areas, as indicated by high MLE values (in red).

The use of NSF substantially impacts both the analysis (Figs. $14 c$ and $14 d$ ) and the wind selection (Figs. 15c and 15d). Furthermore, the wind convergence and divergence lines (as indicated by the high MLE values in red) are well resolved in Fig. 14(c) and $(d)$ and are in line with the 


\begin{tabular}{|c|c|c|c|c|}
\hline $\begin{array}{l}\text { The EUMEESAT } \\
\text { Networof } \\
\text { Satellitie Appolicalion } \\
\text { Facilities }\end{array}$ & Z NWP SAF & $\begin{array}{l}\text { On mesoscale analysis and } \\
\text { ASCAT ambiguity removal }\end{array}$ & $\begin{array}{l}\text { Doc ID } \\
\text { Version } \\
\text { Date }\end{array}$ & $\begin{array}{l}: \text { NWPSAF-KN-VS-014 } \\
: 1.0 \\
: 05-08-2015\end{array}$ \\
\hline
\end{tabular}

ASCAT wind ambiguity general pattern shown in Fig. 13(b). In consequence, the ASCAT-derived wind convergence and divergence patterns in Figs. 15(c) and 15(d) are more realistic and consistent with both the rain rate information (Fig. 13d) and the frontline features as indicated by the high MLE values. In particular, the rather arbitrary and spurious features already discussed and present in Figs. 15(a) (same wind field as Fig. 13c) and 15(b) are not present anymore in Figs. 15(c) and $15(d)$.

Fig. 16 shows the vector difference between the 2DVAR analysis and the ASCAT selected wind solution (i.e., the closest solution to 2DVAR analysis), hereafter referred to as AR residual, for two different tests, i.e., Test 1 (AWDP default settings) and Test 4 (NSF and flexible O/B errors). Test 1 (Fig.16a) shows very high AR residual, in particular over the rainy areas. While Test 4 shows a much smaller AR residual than Test 1. Only relatively high AR residuals are found in Test 4 along the frontal lines, indicating that although the analysis field (Fig. 14d) clearly departs from the ECMWF background (Fig. 13a), as it is dominated by the ASCAT term in 2DVAR, it does not perfectly match the ASCAT general wind pattern (Fig. 13b) in areas of high wind variability (high MLE values as indicated in Fig. 15d). However, the AR errors using Test 4 seem to be very much reduced as compared to those in Test 1.

A thorough and general validation is however required to quantitatively assess the AR errors for the different 2DVAR settings. This is carried out in the next section.
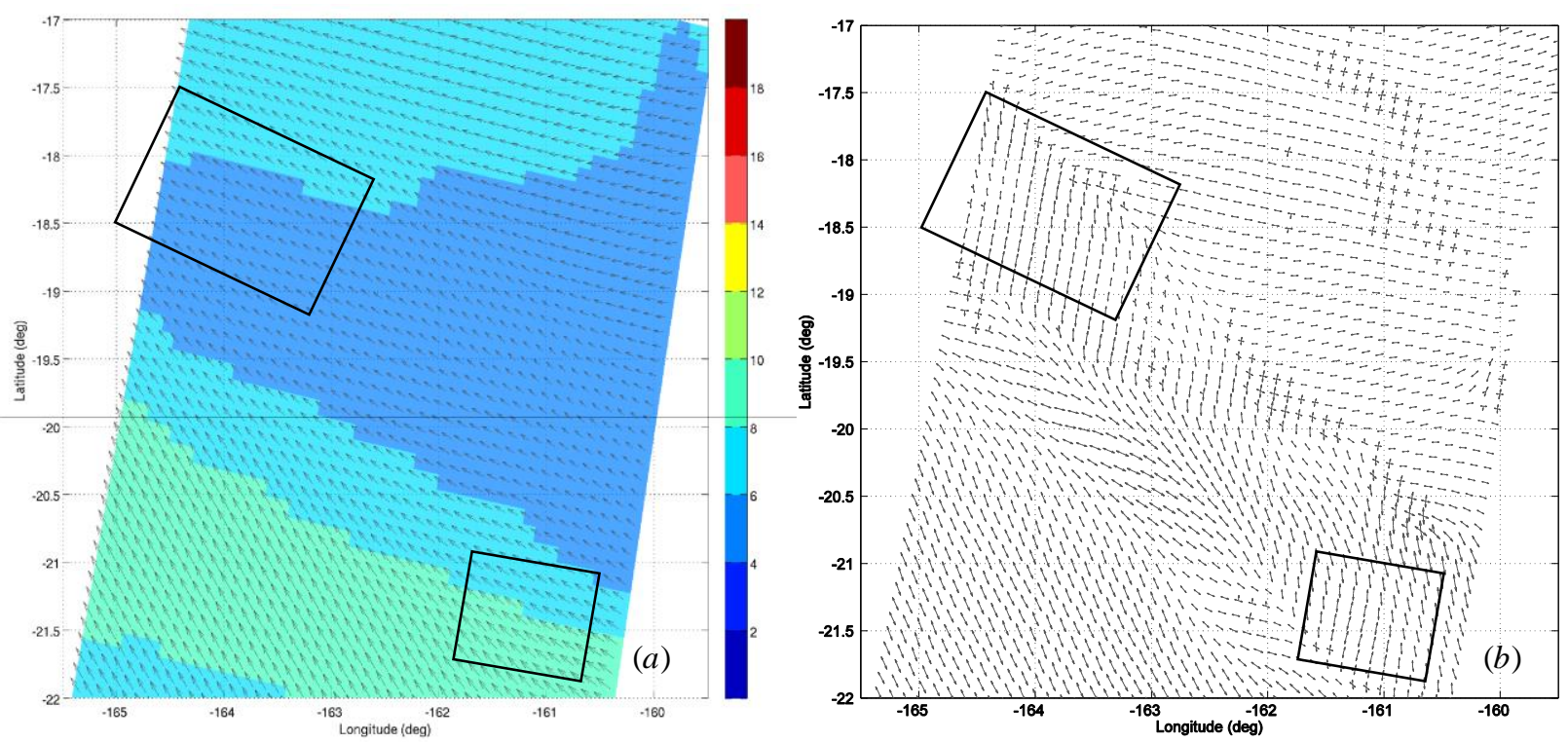


\begin{tabular}{|c|c|c|c|c|}
\hline 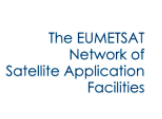 & ₹ NWP SAF & $\begin{array}{l}\text { On mesoscale analysis and } \\
\text { ASCAT ambiguity removal }\end{array}$ & $\begin{array}{l}\text { Doc ID } \\
\text { Version } \\
\text { Date }\end{array}$ & $\begin{array}{l}: \text { NWPSAF-KN-VS-014 } \\
: 1.0 \\
: 05-08-2015\end{array}$ \\
\hline
\end{tabular}
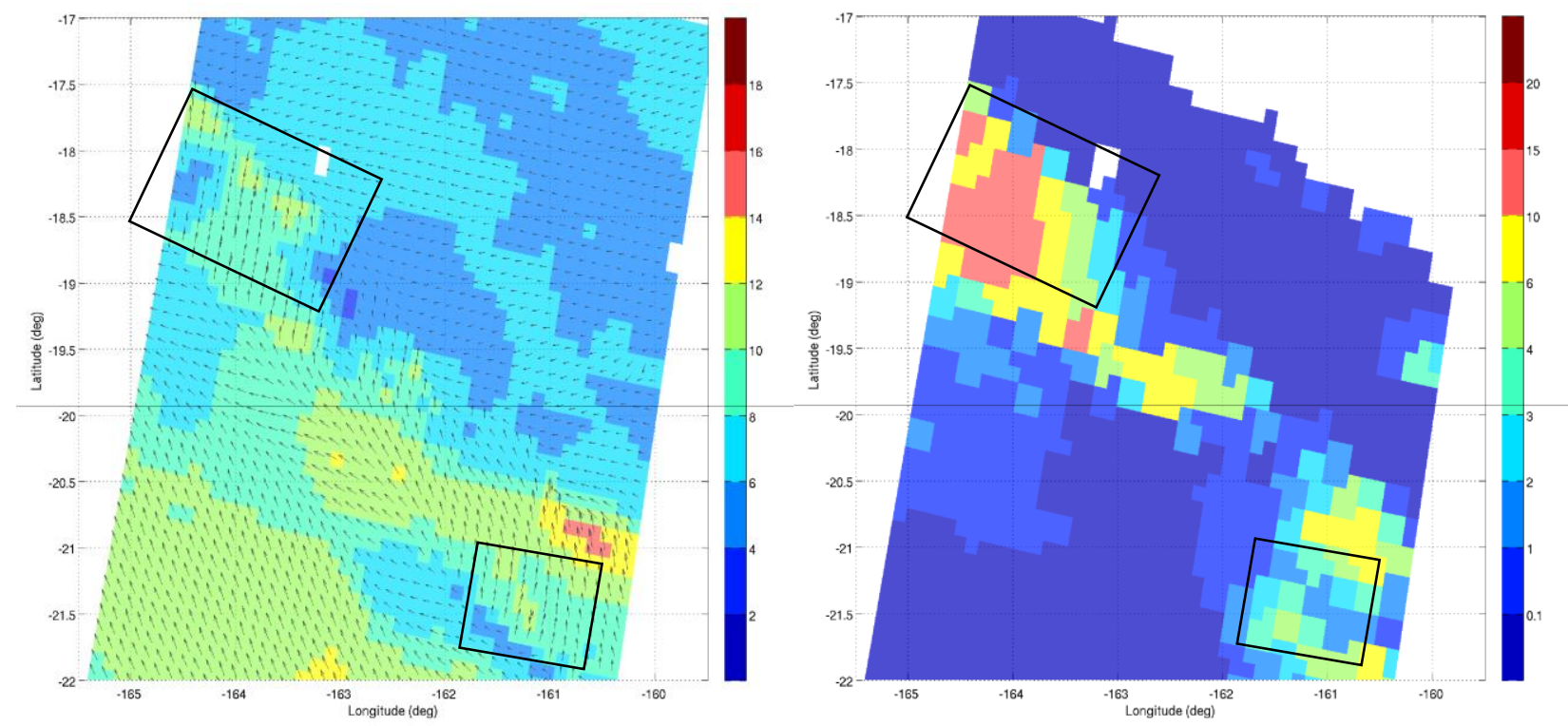

Fig. 13 (a) ECMWF forecasts collocated with ASCAT acquisition on March 10 ${ }^{\text {th }}$ 2009, around 11:48 UTC; $(b)$ ASCAT wind ambiguities; $(c)$ ASCAT selected wind field processed with the operational AWDP settings; $(d)$ Collocated TMI rain distribution. The color legends indicate wind speeds in (a) and (c) and rain rate in (d).
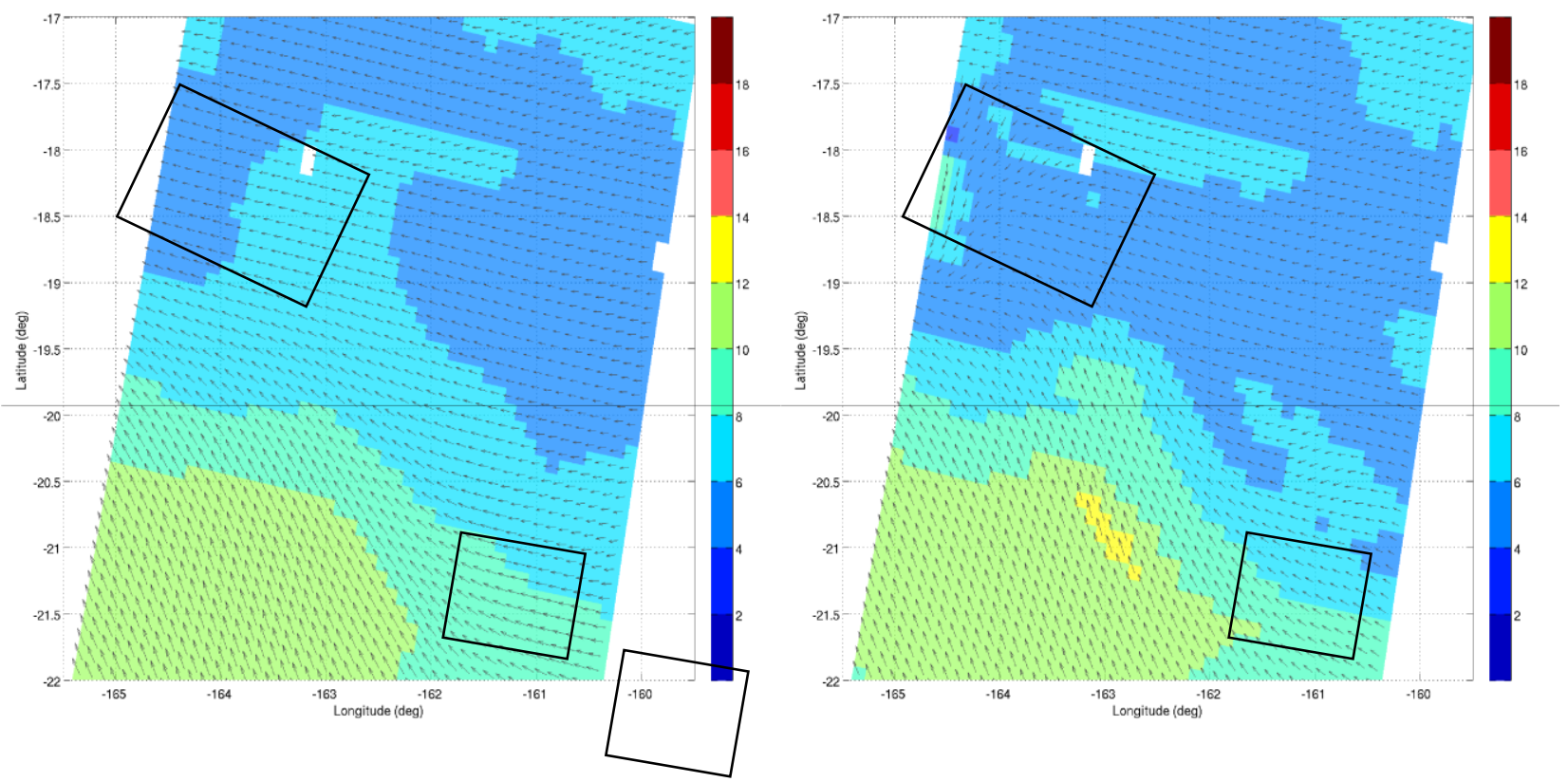


\begin{tabular}{|c|c|c|c|c|}
\hline 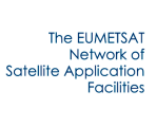 & ₹ NWP SAF & $\begin{array}{l}\text { On mesoscale analysis and } \\
\text { ASCAT ambiguity removal }\end{array}$ & $\begin{array}{l}\text { Doc ID } \\
\text { Version } \\
\text { Date }\end{array}$ & $\begin{array}{l}: \text { NWPSAF-KN-VS-014 } \\
: 1.0 \\
: 05-08-2015\end{array}$ \\
\hline
\end{tabular}
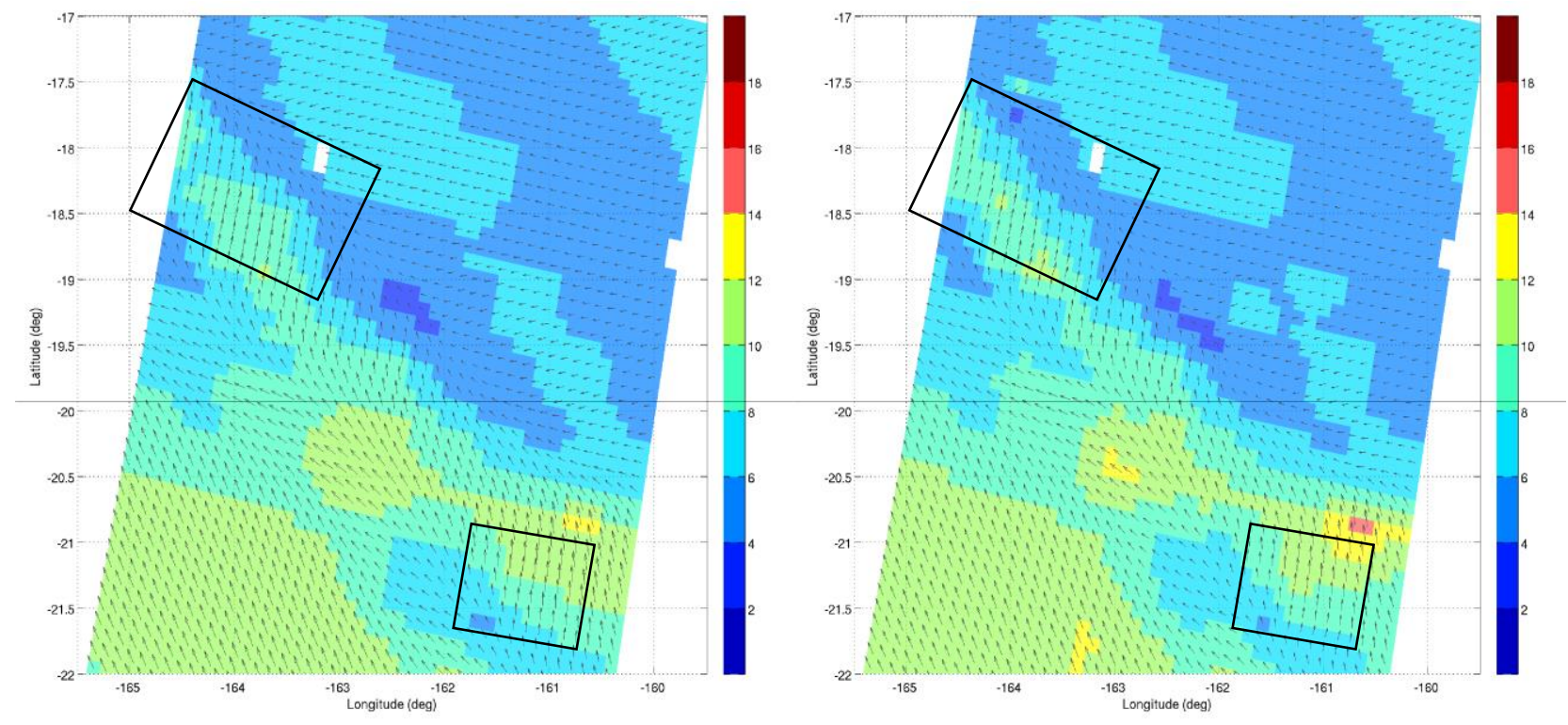

Fig. 14 2DVAR analys is wind field derived from (a): AWDP default setting; (b): GSF and flexible O/B errors; (c) NSF and fixed O/B errors; $(d)$ NSF and flexible O/B errors.
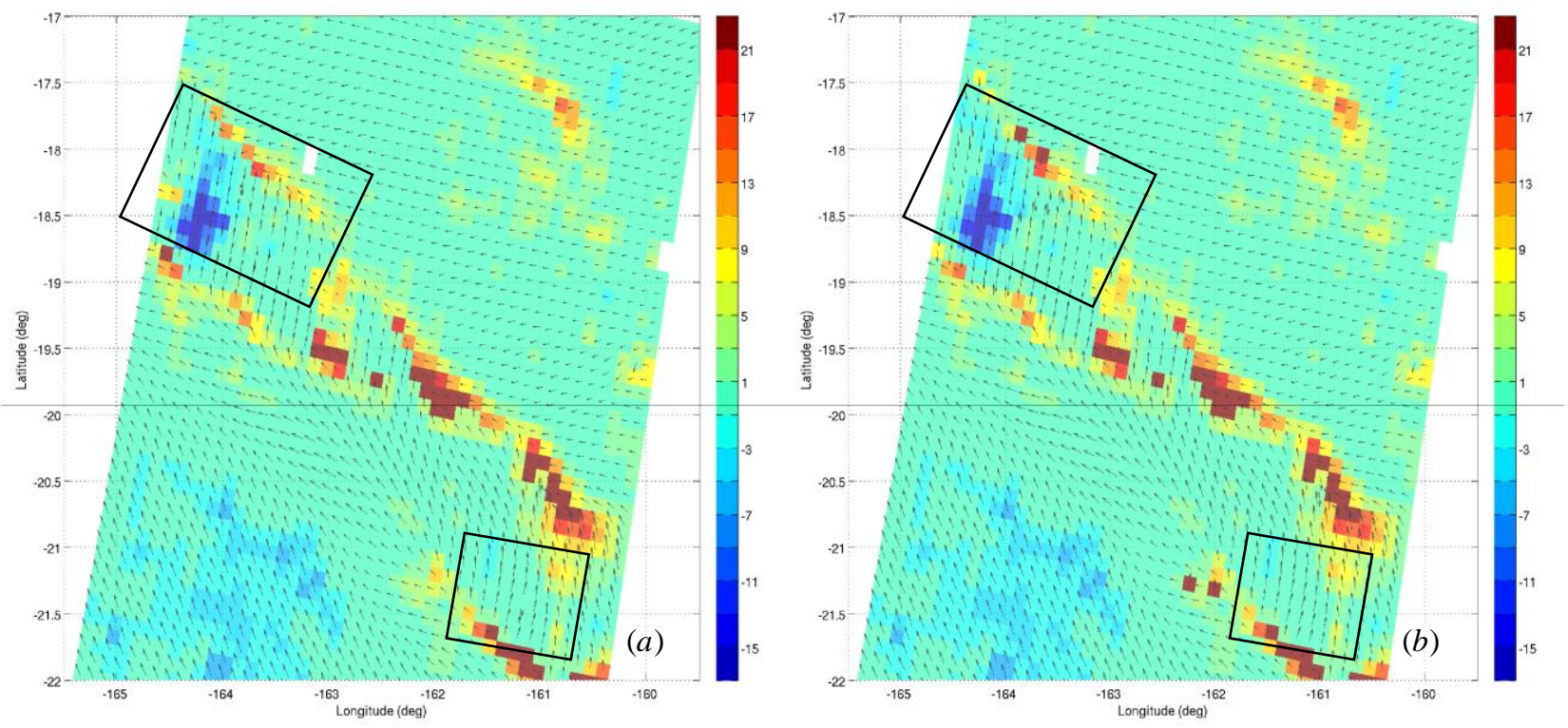


\begin{tabular}{|c|c|c|c|c|}
\hline 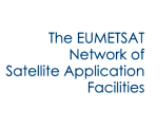 & ₹ NWP SAF & $\begin{array}{l}\text { On mesoscale analysis and } \\
\text { ASCAT ambiguity removal }\end{array}$ & $\begin{array}{l}\text { Doc ID } \\
\text { Version } \\
\text { Date }\end{array}$ & $\begin{array}{l}: \text { NWPSAF-KN-VS-014 } \\
: 1.0 \\
: 05-08-2015\end{array}$ \\
\hline
\end{tabular}
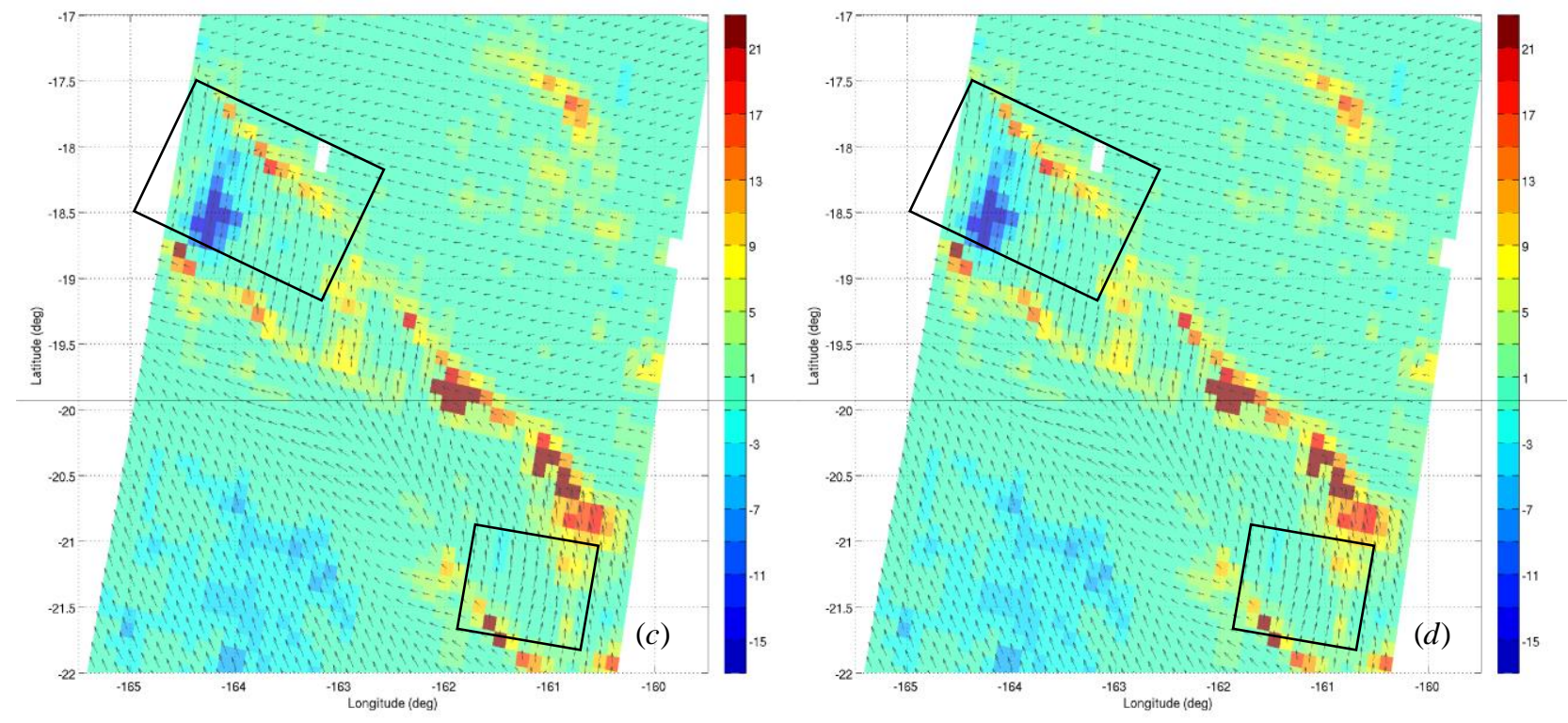

Fig. 15 ASCAT selected wind field superimposed with MLE values (see colour legend) derived from: (a) AWDP default setting; (b) GSF and flexible O/B errors; (c) NSF and fixed O/B errors; (d) NSF and flexible O/B errors. Note that the ASCAT wind field in (a) is the same as that in Fig. 13c.
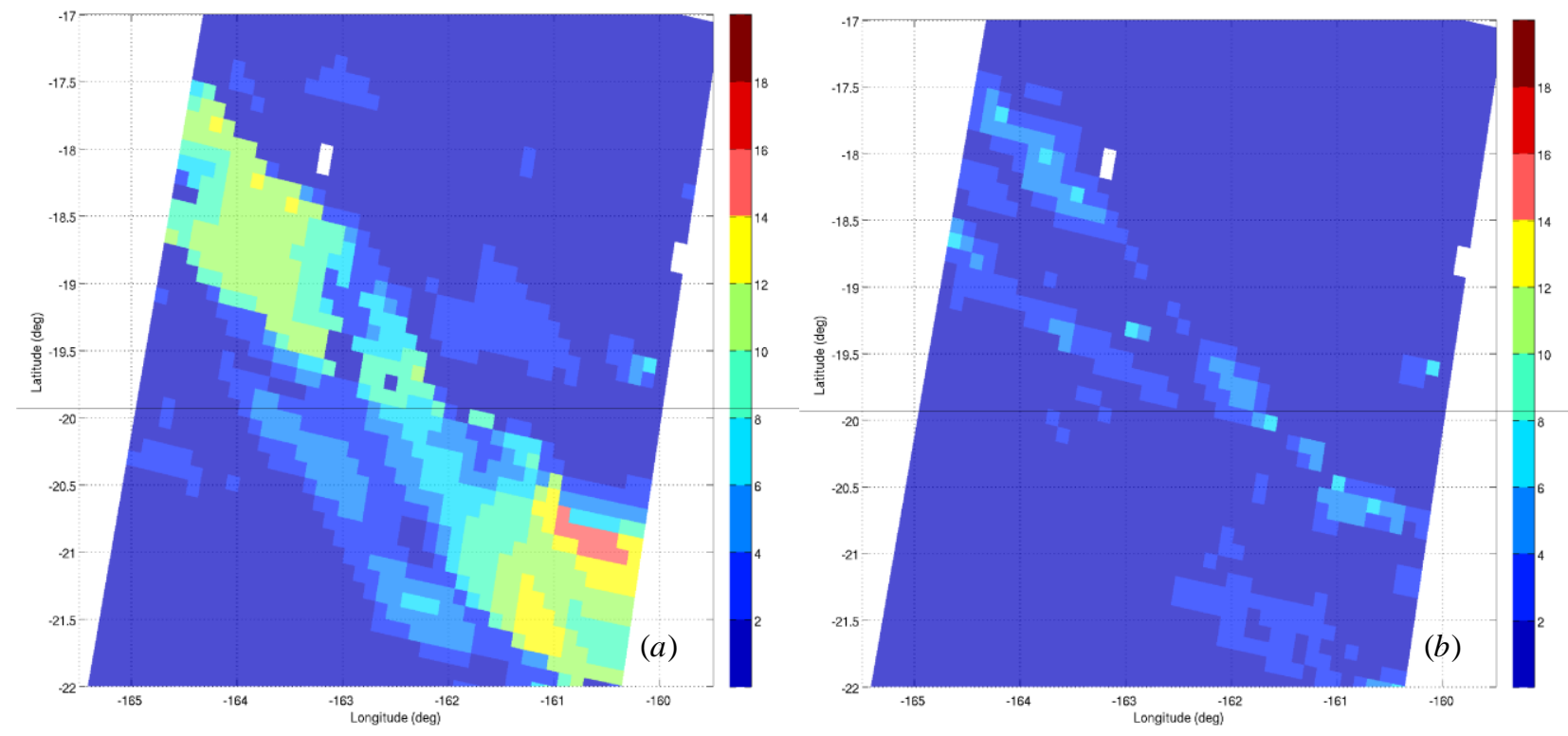

Fig. 16 Distribution of the vector difference between the 2DVAR analys is wind and the ASCAT selected wind solution (i.e., the closest solution to 2DVAR analysis) for: (a) Test 1, default 2DVAR setting; (b) Test 4, 2DVAR with NSF and flexible $\mathrm{O} / \mathrm{B}$ errors.

\subsection{General validation}

The performance of these proposed AR schemes is firstly assessed for different rain conditions. As such, the ASCAT-ECMWF-TMI collocated dataset is separated into several categories according to 


\begin{tabular}{|c|c|c|c|c|}
\hline 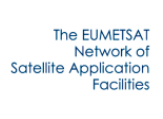 & $\angle$ NWP SAF & $\begin{array}{l}\text { On mesoscale analysis and } \\
\text { ASCAT ambiguity removal }\end{array}$ & $\begin{array}{l}\text { Doc ID } \\
\text { Version } \\
\text { Date }\end{array}$ & $\begin{array}{l}: \text { NWPSAF-KN-VS-014 } \\
: 1.0 \\
: 05-08-2015\end{array}$ \\
\hline
\end{tabular}

the number of ambiguities and the TMI RR value. Table 3 summarizes the number of WVCs for each category. In parenthesis, the percentage of data for which the wind direction ambiguity selection in Test 4 (NSF and flexible O/B errors) is changed with respect to the selected ambiguity in Test 1. Overall, $2 \%$ of wind selections are changed by Test 4 in comparison with Test 1 . For the two-solution cases, the percentage of wind selection change increases with rain rate associated with increasing wind variability, whereas for more-than-2-solution cases, the percentage of wind selection change does not depend on rain rate (probably generally unsettled cases). Note that for the first category ( 2 ambiguities, rain free), the ASCAT selected winds have a slightly lower (1.5\%) VRMS difference against the ECMWF background for Test 4 than for Test 1, while for the other categories they have a larger VRMS difference (not shown). This is a good indicator of the effectiveness of Test 4, since for more stable flows (first category), ECMWF is known to be of high quality whereas for moist convection cases (the other categories), ECMWF is known to have degraded quality winds (Lin et al., 2015a and 2015b).

Table 3: The number of ASCAT-TMI collocations in the defined categories. In parenthesis, the percentage of data for which the wind selection in Test 4 differs from that in Test 1. Only the KNMI QC-accepted data are used in the statistics. Note that arbitrary selection results in 50\%, 67\% and 75\% different selection for $\mathrm{N}$ equals resp. 2, 3 and 4.

\begin{tabular}{|c|c|c|c|c|}
\hline $\begin{array}{r}\text { TMI-RR } \\
(\mathrm{mm} / \mathrm{h})\end{array}$ & 0 (rain free) & $(0,1)$ & {$[1,3)$} & $\geqslant 3$ \\
\hline$N$ ambiguities & & & & \\
\hline 2 & $3,681,828(0.8 \%)$ & $183,787(1.5 \%)$ & $57,435(2.4 \%)$ & $29,970(3.7 \%)$ \\
\hline 3 & $239,448(9.8 \%)$ & $17,723(12.0 \%)$ & $7,265(14.5 \%)$ & $3,718(11.8 \%)$ \\
\hline 4 & $107,611(17.7 \%)$ & $13,396(17.8 \%)$ & $10,105(17.8 \%)$ & $7,896(17.9 \%)$ \\
\hline
\end{tabular}

Table 4 shows the VRMS difference between ASCAT-selected winds and 2DVAR analysis for Test 1. In parenthesis, the percentage of VRMS reduction for Test 4 w.r.t. Test 1 is shown. Table 5 presents the same statistics, but only for those WVCs whose wind direction has been changed in Test 4 w.r.t. that in Test 1 . Note that the VRMS reduction in table 4 is generally higher than that in table 5. On the one hand, the 2DVAR analysis of Test 4 changes not only for the WVCs whose wind direction have been modified w.r.t. Test 1, but also for the unchanged category. On the other hand, the VRMS scores of table 5 are over the more variable conditions. The absolute values in table 5 are much higher than those in table 4 . In general, the 2DVAR analysis of Test 4 is much closer to the selected ASCAT winds than that of Test 1, as expected. Another way to validate the quality of the 2DVAR analysis field is to use ASCAT winds as reference, but only for those 


\begin{tabular}{|c|c|c|c|c|}
\hline 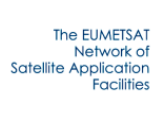 & $\angle$ NWP SAF & $\begin{array}{l}\text { On mesoscale analysis and } \\
\text { ASCAT ambiguity removal }\end{array}$ & $\begin{array}{l}\text { Doc ID } \\
\text { Version } \\
\text { Date }\end{array}$ & $\begin{array}{l}: \text { NWPSAF-KN-VS-014 } \\
: 1.0 \\
: 05-08-2015\end{array}$ \\
\hline
\end{tabular}

conditions where ASCAT is known to be of high quality, i.e., 2-solution cases, rain free, and low MLE values. For such cases the difference between the 2DVAR analysis and its closest ASCAT wind ambiguity (always smaller than $90^{\circ}$ by definition), is substantially reduced with the new settings, indeed indicating that the ASCAT information in the 2DVAR wind analysis is much better fitted. More weight on $\mathrm{J}_{\mathrm{o}}$ does indeed imply increased observation impact and a better fit of the the analysis to the observations. 2-solution, rain free, and low MLE cases (Table 4 and 5, first column/row) represent the vast majority of the WVCs (84.4\%). If a 2DVAR analysis closer to ASCAT is an indication of increased analysis winds quality for such cases (i.e., ASCAT is a very good quality reference under stable conditions), then one can in general also expect a positive impact in 2DVAR for neighbouring WVCs under more unstable conditions. A similar effect is shown for QuikSCAT 2DVAR by Portabella and Stoffelen [2004], i.e., improvement of 2DVAR analysis in certain regions of the QuikSCAT swath positively impacts 2DVAR analysis on neighboring regions. Nevertheless, 2DVAR analysis improvements, notably under moist convection cases, need to be verified.

Table 4: VRMS difference [m/s] between ASCAT-selected winds and 2DVAR analys is for Test 1 (in parenthesis, the percentage of VRMS reduction for Test 4 w.r.t. Test 1 is shown). Only the KNMI QC-accepted WVCs are used.

\begin{tabular}{|c|c|c|c|c|}
\hline $\begin{array}{r}\text { TMI-RR } \\
(\mathrm{mm} / \mathrm{h})\end{array}$ & 0 (rain free) & $(0,1)$ & {$[1,3)$} & $\geqslant 3$ \\
$N$ ambiguities & & & & \\
\hline 2 & $1.04(40.2 \%)$ & $2.19(39.5 \%)$ & $3.02(35.8 \%)$ & $4.43(38.8 \%)$ \\
\hline 3 & $1.44(27.9 \%)$ & $2.31(21.6 \%)$ & $2.96(18.7 \%)$ & $4.49(24.4 \%)$ \\
\hline 4 & $1.37(22.5 \%)$ & $2.14(16.3 \%)$ & $2.67(14.0 \%)$ & $3.83(19.3 \%)$ \\
\hline
\end{tabular}

Table 5: VRMS difference [m/s] between ASCAT-selected winds and 2DVAR analysis for Test 1 (in parenthesis, the percentage of VRMS reduction for Test 4 w.r.t. Test 1 is shown). Only the KNMI QC-accepted WVCs whose wind direction selection has been changed are used.

\begin{tabular}{|c|c|c|c|c|}
\hline $\begin{array}{r}\text { TMI-RR } \\
(\mathrm{mm} / \mathrm{h})\end{array}$ & 0 (rain free) & $(0,1)$ & {$[1,3)$} & $\geqslant 3$ \\
\hline$N$ ambiguities & & & & \\
\hline 2 & $2.01(35.9 \%)$ & $5.14(34.2 \%)$ & $6.25(27.8 \%)$ & $8.08(38.4 \%)$ \\
\hline 3 & $1.69(22.9 \%)$ & $2.81(16.0 \%)$ & $3.37(16.3 \%)$ & $5.20(23.8 \%)$ \\
\hline 4 & $1.64(16.8 \%)$ & $2.67(10.5 \%)$ & $3.42(8.7 \%)$ & $4.75(13.8 \%)$ \\
\hline
\end{tabular}

Analysis improvements are further tested by buoy validation. Table 6(a) shows the VRMS scores of 2DVAR analysis winds (abbr. An) against several reference wind sources (i.e., ECMWF, 


\begin{tabular}{|c|c|c|c|c|}
\hline 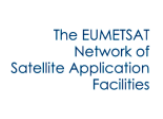 & $\angle$ NWP SAF & $\begin{array}{l}\text { On mesoscale analysis and } \\
\text { ASCAT ambiguity removal }\end{array}$ & $\begin{array}{l}\text { Doc ID } \\
\text { Version } \\
\text { Date }\end{array}$ & $\begin{array}{l}: \text { NWPSAF-KN-VS-014 } \\
: 1.0 \\
: 05-08-2015\end{array}$ \\
\hline
\end{tabular}

$a b b r$. E; MARS buoy wind, abbr. B; buoy 10-min measurement, abbr. $\mathrm{B}_{\mathrm{p}}$; mean buoy wind, abbr. $\mathrm{B}_{\mathrm{m}}$; ASCAT selected wind, $a b b r$. A) for the four mentioned tests. Generally, the 2DVAR with GSF and flexible O/B errors does not lead to closer analysis winds w.r.t. either ECMWF or buoy winds. By using NSF, the 2DVAR analysis is in better agreement with both buoy and ASCAT winds while in worse agreement with ECMWF winds. This indicates that the NSF not only improves the quality but also effectively adds smaller scales to the 2DVAR analysis winds. Note also that the use of flexible O/B errors is only effective when used in combination with NSF. This may be due to the 2DVAR grid size for Test $2(100 \mathrm{~km})$ being much larger than the ASCAT WVC size $(12.5 \mathrm{~km})$, which results in over-smoothed O/B errors since the ASCAT high-resolution information content is averaged into the low-resolution 2DVAR batch grid.

Table 6(b) shows the same statistics as Table 6(a) but only for the WVCs whose wind selection is modified by the new AR schemes. Thus, Tests 2-4 are each compared with Test 1 separately. Despite the small number of cases, the comparison between Test 1 and each new AR scheme generally has the same trend as Table 6(a), expect for the statistics in colored cells. On the one hand, the VRMS statistics are generally much higher than those in Table 6(a), indicating that the highly- variable areas are principally affected by the new AR schemes. On the other hand, most of the studied cases $(75 \%)$ in Table $6(b)$ are under low-wind conditions (buoy wind below $4 \mathrm{~m} / \mathrm{s}$ ). Consequently, for the blue cell, the 2DVAR analysis becomes in better agreement with MARS buoys when the 2 -solution and low-MLE cases are studied solely (Test $1=4.2 \mathrm{~m} / \mathrm{s}$; Test $4=4.1$ $\mathrm{m} / \mathrm{s}$ ). For the green cells, the 2DVAR analysis in Table 6(a) is slightly in better agreement with ASCAT selected winds when the low winds are studied solely (Test $1=1.31 \mathrm{~m} / \mathrm{s}$; Test $2=1.30$ $\mathrm{m} / \mathrm{s})$.

Table 6(a): The VRMS difference between 2DVAR analyzed winds and ECMWF (or buoy winds). Only the QCaccepted WVCs are studied.

\begin{tabular}{|c|c|c|c|c|c|c|c|c|c|}
\hline \multirow{2}{*}{ Experiments } & \multicolumn{4}{|c|}{$\begin{array}{l}\text { ASCAT-ECMWF-MARS buoy } \\
{[\mathrm{m} / \mathrm{s}]}\end{array}$} & \multicolumn{5}{|c|}{$\begin{array}{l}\text { ASCAT-ECMWF-off-line buoy } \\
\text { (mean buoy winds } B_{m} \text { ) }[\mathrm{m} / \mathrm{s}]\end{array}$} \\
\hline & An.v.E & An.v.B & An.v.A & $N$ & An.v.E & An.v. $B_{p}$ & An.v. $B_{m}$ & An.v.A & $N$ \\
\hline Test 1 & 1.93 & 2.25 & 1.35 & \multirow{4}{*}{13821} & 1.92 & 2.05 & 1.89 & 1.28 & \multirow{4}{*}{6923} \\
\hline Test 2 & 1.93 & 2.29 & 1.37 & & 1.92 & 2.07 & 1.91 & 1.29 & \\
\hline Test 3 & 2.13 & 2.10 & 0.86 & & 2.09 & 1.89 & 1.73 & 0.83 & \\
\hline Test 4 & 2.12 & 2.11 & 0.88 & & 2.08 & 1.88 & 1.72 & 0.84 & \\
\hline
\end{tabular}

Table 6(b): The VRMS difference between 2DVAR analyzed winds and ECMWF (or buoy winds). For Tests 2-4, the WVCs which selected solutions are different from Test 1 are each analyzed. 


\begin{tabular}{|c|c|c|c|c|}
\hline $\begin{array}{l}\text { The EUMEESAT } \\
\text { Netrot } \\
\text { Satellite Appolichof of } \\
\text { Facilities }\end{array}$ & 2 NWP SAF & $\begin{array}{l}\text { On mesoscale analysis and } \\
\text { ASCAT ambiguity removal }\end{array}$ & $\begin{array}{l}\text { Doc ID } \\
\text { Version } \\
\text { Date }\end{array}$ & $\begin{array}{l}: \text { NWPSAF-KN-VS-014 } \\
: 1.0 \\
: 05-08-2015\end{array}$ \\
\hline
\end{tabular}

\begin{tabular}{|c|c|c|c|c|c|c|c|c|c|}
\hline \multirow{2}{*}{ Experiments } & \multicolumn{4}{|c|}{$\begin{array}{l}\text { ASCAT-ECMWF-MARS buoy } \\
{[\mathrm{m} / \mathrm{s}]}\end{array}$} & \multicolumn{5}{|c|}{$\begin{array}{l}\text { ASCAT-ECMWF-off-line buoy } \\
\text { (mean buoy winds } B_{m} \text { ) }[\mathrm{m} / \mathrm{s}]\end{array}$} \\
\hline & An.v.E & An.v.B & An.v.A & $N$ & An.v.E & An.v. $B_{p}$ & An.v. $B_{m}$ & An.v.A & $N$ \\
\hline Test 1 & 3.3 & 4.0 & 3.3 & \multirow{2}{*}{142} & 3.2 & 4.3 & 4.1 & 3.28 & \multirow{2}{*}{69} \\
\hline Test 2 & 3.4 & 4.7 & 3.4 & & 3.5 & 4.3 & 4.3 & 3.06 & \\
\hline Test 1 & 2.8 & 3.7 & 2.7 & \multirow{2}{*}{317} & 2.7 & 3.4 & 3.3 & 2.4 & \multirow{2}{*}{148} \\
\hline Test 3 & 3.2 & 3.6 & 1.7 & & 3.0 & 3.3 & 3.2 & 1.6 & \\
\hline Test 1 & 3.0 & 3.82 & 2.7 & \multirow{2}{*}{322} & 2.9 & 3.6 & 3.5 & 2.4 & \multirow{2}{*}{148} \\
\hline Test 4 & 3.3 & 3.83 & 1.8 & & 3.1 & 3.3 & 3.2 & 1.7 & \\
\hline
\end{tabular}

Table 7 presents the same statistics as Table 6 but for ASCAT selected winds instead of 2DVAR analysis winds. None of the proposed AR methods shows remarkably better agreement with both buoy and ECMWF winds than Test 1 (default AWDP settings). This is as expected, since only about $1-2 \%$ of wind ambiguity selections are modified by the new configurations (i.e., Tests 2-4) and this $1-2 \%$ generally corresponds to areas of high spatial and temporal variability, where both ECMWF and buoy measurements are the least representative of the ASCAT resolved scales (25 $\mathrm{km}$ ). Slightly lower VRMS scores are obtained for tests 3 and 4 (i.e., when using NSF) than for tests 1 and 2 (i.e., GSF) when validating against buoy winds, especially against $B_{p}$ and $B_{m}$ (which are slightly more accurate than the 1-m/s binned MARS buoy winds, as shown by Lin et al., 2015b). In the latter case, the variance reductions are about $2 \%$ and $4 \%$ for Test 3 and Test 4 respectively. Since these values are close to the three-sigma uncertainty (3.6\%), the difference is not statistically significant. However, the VRMS difference between ASCAT and 2DVAR analysis is indeed remarkably reduced by incorporating NSF in the 2DVAR analysis. In line with the conclusions of the previous section, this is an indication that, in contrast with GSF, NSF provides more weight to the observational term (ASCAT wind ambiguities) than to the background term (ECMWF). Regarding the WVCs whose wind selection is modified by the new AR schemes, the comparison between Test 1 and each new AR scheme in Table 7(b) has the same trend as Table 7( $a)$.

Moreover, all VRMS scores against $\mathrm{B}_{\mathrm{m}}$ are lower than those for $\mathrm{B}$ and $\mathrm{B}_{\mathrm{p}}$, indicating that $\mathrm{B}_{\mathrm{m}}$ is more representative of the ASCAT resolved scales, as shown by Lin et al. (2015b).

Table 7(a): The VRMS difference between ASCAT selected solutions and ECMWF (or buoy) winds. Only the QC-accepted WVCs are studied.

\begin{tabular}{|c|c|c|c|c|c|c|c|}
\hline \multirow{2}{*}{$\begin{array}{c}\text { Data set } \\
\text { Experiments }\end{array}$} & \multicolumn{3}{|c|}{$\begin{array}{c}\text { ASCAT-ECMWF-MARS } \\
\text { buoy [m/s] }\end{array}$} & \multicolumn{3}{c|}{$\begin{array}{c}\text { ASCAT-ECMWF-off-line buoy } \\
\text { (mean buoy winds) [m/s] }\end{array}$} \\
\cline { 2 - 8 } & A.v.E & A.v.B & $N$ & A.v.E & A.v.B & A.v. $\mathrm{B}_{\mathrm{m}}$ & $N$ \\
\hline Test 1 & 2.37 & 2.17 & 13821 & 2.30 & 1.93 & 1.80 & 6923 \\
\hline
\end{tabular}




\begin{tabular}{|c|c|c|c|c|}
\hline 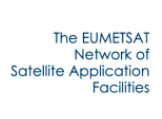 & Z NWP SAF & $\begin{array}{l}\text { On mesoscale analysis and } \\
\text { ASCAT ambiguity removal }\end{array}$ & $\begin{array}{l}\text { Doc ID } \\
\text { Version } \\
\text { Date }\end{array}$ & $\begin{array}{l}: \text { NWPSAF-KN-VS-014 } \\
: 1.0 \\
: 05-08-2015\end{array}$ \\
\hline
\end{tabular}

\begin{tabular}{|c|c|c|c|c|c|}
\hline Test 2 & 2.37 & 2.18 & 2.30 & 1.91 & 1.79 \\
\hline Test 3 & 2.37 & 2.13 & 2.30 & 1.91 & 1.78 \\
\hline Test 4 & 2.36 & 2.14 & 2.29 & 1.89 & 1.75 \\
\hline
\end{tabular}

Table 7(b): The VRMS difference between ASCAT selected solutions and ECMWF (or buoy) winds. For Tests 24, the WVCs which selected solutions are different from Test 1 are analyzed.

\begin{tabular}{|c|c|c|c|c|c|c|c|}
\hline \multirow{2}{*}{ Experiments } & \multicolumn{3}{|c|}{$\begin{array}{l}\text { ASCAT-ECMWF-MARS } \\
\text { buoy }[\mathrm{m} / \mathrm{s}]\end{array}$} & \multicolumn{4}{|c|}{$\begin{array}{l}\text { ASCAT-ECMWF-off-line buoy (mean } \\
\text { buoy winds) }[\mathrm{m} / \mathrm{s}]\end{array}$} \\
\hline & A.v.E & A.v.B & $N$ & A.v.E & A.v. $B_{p}$ & A.v. $B_{m}$ & $N$ \\
\hline Test 1 & 5.0 & 5.1 & \multirow{2}{*}{142} & 5.1 & 6.0 & 5.8 & \multirow{2}{*}{69} \\
\hline Test 2 & 4.9 & 5.7 & & 4.9 & 5.2 & 5.4 & \\
\hline Test 1 & 4.1 & 4.9 & \multirow{2}{*}{317} & 3.7 & 4.4 & 4.4 & \multirow{2}{*}{148} \\
\hline Test 3 & 4.1 & 4.1 & & 3.9 & 3.9 & 3.8 & \\
\hline Test 1 & 4.3 & 4.9 & \multirow{2}{*}{322} & 3.9 & $\begin{array}{l}4.7 \\
\end{array}$ & 4.6 & \multirow{2}{*}{148} \\
\hline Test 4 & 4.2 & 4.4 & & 3.6 & 3.7 & 3.6 & \\
\hline
\end{tabular}

\subsection{Spatial scales}

In 2DVAR the analysis' objective is to fit all scales present in the ambiguous scatterometer winds, while in Numertical Weather Prediction the the degrees of freedom in the forecasting model should be initialized without creating small-scale noise. We now check how these different objectives are met in 2DVAR through a spectral analysis. 


\begin{tabular}{|c|c|c|c|c|}
\hline 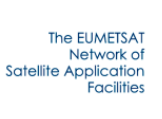 & ₹ NWP SAF & $\begin{array}{l}\text { On mesoscale analysis and } \\
\text { ASCAT ambiguity removal }\end{array}$ & $\begin{array}{l}\text { Doc ID } \\
\text { Version } \\
\text { Date }\end{array}$ & $\begin{array}{l}: \text { NWPSAF-KN-VS-014 } \\
: 1.0 \\
: 05-08-2015\end{array}$ \\
\hline
\end{tabular}
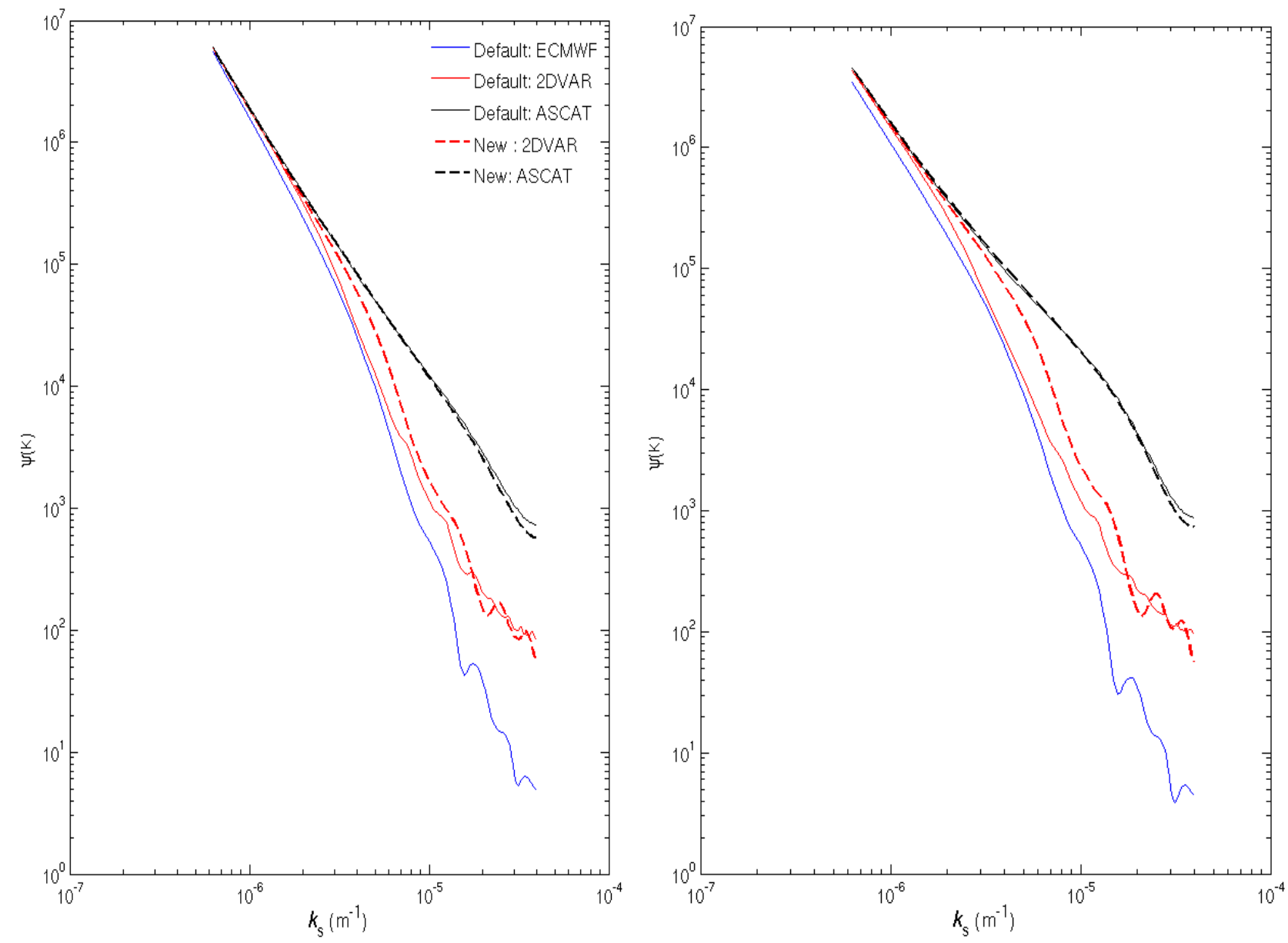

Fig. 17 Across- (left) and along-track (right) spatial wind spectra as a function of wave number after Fourier transform. "New" refers to Test 4 and "Default" to Test 1 . While the ASCAT winds show a very similar spectrum for both, the "New" 2DVAR analysis shows enhanced mesoscale content.

Figure 17 shows spectra of the Test 1 (default) and Test 4 (New) cases. As anticipated, the ECMWF spectra are identical, while showing a steep descent. The selected ASCAT wind spectra are also very similar, so the small fraction of differing selections has seemingly little impact on the spectral behaviour in line with 3D turbulence on atmospheric scales below $500 \mathrm{~km}$ (cf. Vogelzang et al., 2011b). More interestingly, the Test-1 and Test-4 2DVAR analysis spectra are in fact different, with Test-4 spectra showing more content on the mesoscales. This is in line with the increased weight of $\mathrm{J}_{\mathrm{O}}$ due to NSF and O/B weights, but less so with the low-pass filtering characteristics of the broader background error structure functions. Given the favourable validation results in Test 4 over the scatterometer swath, apparently the former aspect dominates the analysis quality over the scatterometer swath. Moreover, a numerically fitted background error structure may 


\begin{tabular}{|c|c|c|c|c|}
\hline 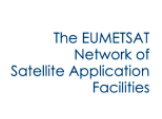 & Z NWP SAF & $\begin{array}{l}\text { On mesoscale analysis and } \\
\text { ASCAT ambiguity removal }\end{array}$ & $\begin{array}{l}\text { Doc ID } \\
\text { Version } \\
\text { Date }\end{array}$ & $\begin{array}{l}: \text { NWPSAF-KN-VS-014 } \\
: 1.0 \\
: 05-08-2015\end{array}$ \\
\hline
\end{tabular}

generally perform better than a Gaussian one. The additional mesoscale content is clearly favourable for 2DVAR in order to perform ambiguity removal on the scales resolved by ASCAT.

Is this setting similarly favourable in mesoscale NWP data assimilation? First, a favourable fit within the ASCAT swath does not imply a better overall analysis, since outside the ASCAT swath, notably between swaths and in the vertical, an increased $J_{0}$ weight often leads to problems of overfitting, thus generating artefacts and potentially detrimental forecast impact. Independent verification of the analysis fields beyond the swath regions is thus needed. Second, the aim of meteorological analysis is to initialize the degrees of freedom of the forecast model. When 3D turbulence (on scales smaller than $500 \mathrm{~km}$ ) is largely dissipated in a forecast model, then initialisation in the analysis appears not effective and possibly counterproductive.

Third, although EDA prescribes variable background error covariances, it does not imply variable observation error variances, while in this manuscript we have shown that background and observation errors will both go up in variable atmospheric conditions. More advanced error modelling as described here may benefit data assimilation. 


\begin{tabular}{|c|c|c|c|c|}
\hline 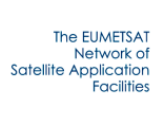 & Z NWP SAF & $\begin{array}{l}\text { On mesoscale analysis and } \\
\text { ASCAT ambiguity removal }\end{array}$ & $\begin{array}{l}\text { Doc ID } \\
\text { Version } \\
\text { Date }\end{array}$ & $\begin{array}{l}: \text { NWPSAF-KN-VS-014 } \\
: 1.0 \\
: 05-08-2015\end{array}$ \\
\hline
\end{tabular}

\section{Conclusions}

Global NWP does not well resolve the mesoscale sea surface wind flow under increased wind variability conditions, such as in the vicinity of low-pressure centers, frontal lines, and rain. By using the current 2DVAR scheme in AWDP, the ECMWF background winds and their estimated error variance structure dominate the resulting 2DVAR analysis, which can lead to ASCAT ambiguity removal errors under increased wind variability conditions. The influence of the ECMWF background errors on the 2DVAR analysis can be reduced by increasing the background error SDs (or decreasing the observation error SDs), and/or increasing the background error correlation length. In this study, an adaptive 2DVAR approach using situation-dependent observation/background errors and numerical background error structure function is proposed to improve ASCAT ambiguity removal. Several experiments using different 2DVAR settings are carried out in order to optimize the 2DVAR approach for ASCAT ambiguity removal, which currently uses GSF and fixed O/B errors. As a consequence, the 2DVAR analysis becomes much closer to the selected ASCAT winds. For those conditions where ASCAT is known to be of high quality, i.e., 2-solution cases, rain free, and low MLE values, the difference between the 2DVAR analysis and its closest ASCAT wind ambiguity (always smaller than $90^{\circ}$ by definition) is substantially reduced with the new settings, indeed indicating that the ASCAT information in the 2DVAR wind analysis is much better fitted.

Even though the combination of GSF and flexible O/B errors shows some improvement in the cyclone case, it generally does not produce better wind selection than the default setting. In fact, the ratio of observation and background error is generally close to the default setting. In contradiction, by adopting NSF in 2DVAR, about $2 \%$ of the wind selections are modified w.r.t. the default 2DVAR scheme, since the much broader structure function effectively decreases the background weight $\mathrm{J}_{\mathrm{b}}$. Furthermore, the 2DVAR analysis becomes much closer to the selected ASCAT winds. The combination of NSF and flexible O/B errors slightly further improves the ASCAT wind quality, when compared against continuous buoy winds.

The 2DVAR analysis winds are proven to be of higher quality and resolution, showing smallerscale convergence/divergence features. In consequence, arbitrary wind ambiguity selections due to a poor background field, sometimes leading to spurious wind convergence and divergence features in the ASCAT selected field, are reduced with the new settings, while spatially-consistent 


\begin{tabular}{|c|c|c|c|c|}
\hline 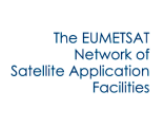 & Z NWP SAF & $\begin{array}{l}\text { On mesoscale analysis and } \\
\text { ASCAT ambiguity removal }\end{array}$ & $\begin{array}{l}\text { Doc ID } \\
\text { Version } \\
\text { Date }\end{array}$ & $\begin{array}{l}: \text { NWPSAF-KN-VS-014 } \\
: 1.0 \\
: 05-08-2015\end{array}$ \\
\hline
\end{tabular}

convergence/divergence features, seen in ASCAT ambiguity streamlines, are introduced in the analysis.

EDA errors appear rather smooth with respect to the mesoscale variability seen in the ECMWF wind errors by ASCAT. However, whereas in 4D-var the observation errors are non-adaptive, the TC method indicates that both background and observation errors are dependent on meteorological condition in very similar ways, thus reducing the adaptiveness of the relative observation weights.

This work can be further extended to improve higher dimensional variational (e.g., 4DVAR) data assimilation schemes.

This work is based on the following publications:

Lin, W., M. Portabella, A. Stoffelen, J. Vogelzang and A. Verhoef, “ASCAT wind quality under high sub-cell wind variability conditions," J. Geophys. Res. Oceans, in press, $2015 b$.

Lin et al., to be submitted to QJRS in August 2015. 


\begin{tabular}{|c|c|c|c|c|}
\hline 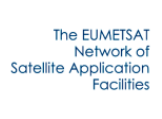 & Z NWP SAF & $\begin{array}{l}\text { On mesoscale analysis and } \\
\text { ASCAT ambiguity removal }\end{array}$ & $\begin{array}{l}\text { Doc ID } \\
\text { Version } \\
\text { Date }\end{array}$ & $\begin{array}{l}: \text { NWPSAF-KN-VS-014 } \\
: 1.0 \\
: 05-08-2015\end{array}$ \\
\hline
\end{tabular}

\section{References}

Bonavita, M., L. Isaksen, and E. Hólm, "On the use of EDA background error variances in the ECMWF 4D-Var,” Q.J.R. Meteorol. Soc., 138: 1540-1559, 2012. doi: 10.1002/qj.1899

Daley, R., "Atmospheric Data Analysis," Cambridge University Press, Cambridge, New York, USA, 1991.

Lin, W., M. Portabella, A. Stoffelen, and A. Verhoef, "On the characteristics of ASCAT direction ambiguities,” Atmos. Meas. Tech., 6, 1053-1060, 2013.

Lin, W., M. Portabella, A. Stoffelen, A. Turiel, and A. Verhoef, "Rain identification in ASCAT winds using singularity analysis," IEEE Trans. Geosci. Remote. Sens. Lett., 11(9), 1519-1523, 2014.

Lin, W., M. Portabella, A. Stoffelen, A. Verhoef, and A. Turiel, "ASCAT wind quality control near rain," IEEE Trans. on Geoscience and Rem. Sens., 53(8), pp.4165-4177, 2015 a.

Lin, W., M. Portabella, A. Stoffelen, J. Vogelzang, and A. Verhoef, "ASCAT wind quality under high sub-cell wind variability conditions," J. Geophys. Res. Oceans, in press, $2015 b$.

Lin et al., 2DVAR paper, to be submitted to QJRS in August 2015.

Liu, W.T., K. B. Katsaros, and J. A. Businger, "Bulk parameterization of air-sea exchanges of heat and water vapor including the molecular constraints in the interface," J. Atmos. Sci., 36(9), 1722$1735,1979$.

Marseille, G.J., A. Stoffelen, H. Schyberg, L. Megner, and H. Kornich, "VHAMP: Vertical and Horizontal Aeolus Measurement Positioning," ESA contract reports, 2013. Final report available: http//www.knmi.nl/ marseill/publications/

Pont, O., A. Turiel, and H. Yahia, "An optimized algorithm for the evaluation of local singularity exponents in digital signals," in: Aggarwal, J., Barneva, R., Brimkov,V., Koroutchev, K., Korutcheva, E. (eds.) 14th International Workshop, IWCIA2011. Lecture Notes in Computer Science (LNCS), vol. 6636, pp. 346-357. Springer, Madrid, Spain, 2011. Available: http//hal.inria.fr/inria-00581057/en/.

Portabella, M. and A. Stoffelen, “A probabilistic approach for SeaWinds data assimilation," Quart. J. Royal Meteor. Soc., 130, 596, 127-159, doi:10.1256/qj.02.205, 2004.

Portabella, M., A. Stoffelen, A. Verhoef, and J. Verspeek, "A new method for improving scatterometer wind quality control," IEEE Trans. Geosci. Remote. Sens. Lett., 9(4), 579-583, 2012.

Stoffelen, A. and M. Portabella, "On Bayesian Scatterometer Wind Inversion", IEEE Transactions on Geoscience and Remote Sensing, 44(6), 1523-1533, 2006, doi:10.1109/TGRS.2005.862502. 


\begin{tabular}{|c|c|c|c|c|}
\hline 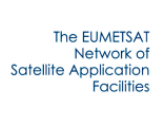 & Z NWP SAF & $\begin{array}{l}\text { On mesoscale analysis and } \\
\text { ASCAT ambiguity removal }\end{array}$ & $\begin{array}{l}\text { Doc ID } \\
\text { Version } \\
\text { Date }\end{array}$ & $\begin{array}{l}: \text { NWPSAF-KN-VS-014 } \\
: 1.0 \\
: 05-08-2015\end{array}$ \\
\hline
\end{tabular}

Stoffelen, A., "Toward the true near-surface wind speed: Error modeling and calibration using triple collocation," J. Geophys. Res., 103(C4), 7755-7766, doi:10.1029/97JC03180, 1998.

Stoffelen, A. and D. Anderson, "Ambiguity removal and assimilation of scatterometer data," Quart. J. Royal Meteor. Soc. 123, 538: 491-518, 1997a. DOI: 10.1002/qj.49712353812.

Stoffelen, A. and D. Anderson, "Scatterometer data interpretation: measurement space and inversion," J. Atmos. Ocean. Technol., 14, 1298-1313, $1997 \mathrm{~b}$.

Turiel, A., H. Yahia, and C. Pérez-Vicente, "Microcanonical multifractal formalism: a geometrical approach to multifractal systems. Part I: Singularity analysis," Journal of Physics A, 41:015501, 2008.

Verhoef, A., M. Portabella, A. Stoffelen, and H. Hersbach, "CMOD5.n- the CMOD5 GMF for neutral winds," KNMI, De Bilt, The Netherlands, Ocean and Sea Ice SAF Technical Note, SAF/OSI/CDOP/KNMI/TEC/TN/3 $165 \quad$ v.1. 1 Available http $/ /$ www.knmi.nl/scatterometer/publications/.

Vogelzang, J., "Two dimensional variational ambiguity removal (2DVAR)," Report NWPSAF-KNTR-004 Version 1.0, UKMO, UK, 2007.

Vogelzang, J., "Estimation of background error correlation functions," Report NWPSAF-KN-TR023 Version 1.0, UKMO, UK, 2014

Vogelzang, J., A. Stoffelen, A. de Verhoef, and H. Bonekamp, "Validation of two-dimensional variational Ambiguity removal on SeaWinds scatterometer data," J. Atmos. Ocean. Technol., vol. 26, no. 7, pp. 1229-1245, Jul. 2010.

Vogelzang, J., and A. Stoffelen, "NWP model error structure functions obtained from scatterometer winds," IEEE Trans. Geosci. Remote Sens., vol. 50, no. 7, pp. 2525-2533, Jul. 2011 a.

Vogelzang, J., A. Stoffelen, A. Verhoef, and J. Figa-Saldaña, "On the quality of high-resolution scatterometer winds," J. Geophys. Res., 116, C10033, doi:10.1029/2010JC006640, 2011 b.

Vogelzang, J., G.P. King, and A. Stoffelen, "Spatial variances of wind fields and their relation to second-order structure functions and spectra," J. Geophys. Res.Oceans, 120, doi:10.1002/2014JC010239, 2015. 